\title{
Acquired Demyelinating Disorders of the CNS in Children
}

\author{
R. Govender ${ }^{1}$, Jo M. Wilmshurst ${ }^{2}$ and Nicky Wieselthaler ${ }^{2}$ \\ ${ }^{1}$ University of Kwa-Zulu Natal, Durban \\ ${ }^{2}$ University of Cape Town, Cape Town \\ South Africa
}

\section{Introduction}

Acquired Demyelinating disorders of the central nervous system in children span a wide spectrum. These conditions may be mono-phasic and self limiting or multi-phasic. Children may present with mono-focal (optic neuritis) or multi-focal (Acquired demyelinating encephalomyelitis) clinical findings.

These demyelinating disorders also share many common clinical, radiological and laboratory features. Early classification of whether the disease is either mono- or multiphasic has diagnostic and therapeutic implications. Identification of patients who present with a first demyelinating event and are at risk for evolution to multiple sclerosis, allows disease modifying therapeutic agents to be initiated early and thus preserve brain function. The aetiology of acquired demyelinating conditions is multi-factorial namely - genetic, postinfectious, post-immunization and possibly due to a T-cell mediated auto-immune response to myelin basic protein triggered by an infection or immunization.

This chapter will cover the aetiologies, consensus definitions, clinical presentation, neuroimaging, evolution and therapeutic advances in acquired demyelinating disorders in children. The pivotal role of neuro-imaging in unraveling the pathology, aetiology and diagnosis of these disorders is also highlighted.

Clinical and neuro-imaging features of other acquired white matter lesions (via infections, toxins, nutritional deficiencies, and osmotic myelinolysis) disease are also discussed.

\section{Definitions}

The International Paediatric Multiple Sclerosis Study group in 2007 proposed consensus definitions for the demyelinating disorders in children (Krupp et al., 2007). This group was convened to define an operational classification system for the demyelinating disorders. Consensus definitions aid in standardization of diagnosis, investigation, management and further research of these conditions.

\section{Imaging techniques for white matter disorders}

Magnetic Resonance Imaging (MRI) is the diagnostic modality of choice for evaluating white matter disorders. Sophisticated applications of magnetic resonance technology, such 


\begin{tabular}{|c|c|}
\hline & Definition \\
\hline $\begin{array}{c}\text { Acquired Demyelinating } \\
\text { Encephalomyelitis (ADEM) }\end{array}$ & $\begin{array}{l}\text { A first clinical event with a presumed inflammatory or } \\
\text { demyelinating cause, with acute or sub-acute onset that } \\
\text { affects multifocal areas of the CNS and must include } \\
\text { encephalopathy }\end{array}$ \\
\hline Recurrent ADEM & $\begin{array}{l}\text { New event of ADEM with a recurrence of the initial } \\
\text { symptoms and signs, } 3 \text { or more months after the first } \\
\text { ADEM event, without involvement of new clinical } \\
\text { areas by history, examination, or neuro-imaging }\end{array}$ \\
\hline $\begin{array}{l}\text { Multi-phasic Demyelinating } \\
\text { Encephalomyelitis (MDEM) }\end{array}$ & $\begin{array}{l}\text { ADEM followed by a new clinical event also meeting } \\
\text { criteria for ADEM, but involving new anatomic areas } \\
\text { of the CNS as confirmed by history, neurologic } \\
\text { examination, and neuro-imaging. The event must } \\
\text { develop within } 3 \text { months of the initial event. }\end{array}$ \\
\hline Neuromyelitis Optica (NMO) & $\begin{array}{l}\text { Must have optic neuritis and acute myelitis as major } \\
\text { criteria and a spinal MRI lesion extending over three or } \\
\text { more segments or be NMO positive on antibody testing }\end{array}$ \\
\hline $\begin{array}{l}\text { Acute Transverse Myelitis } \\
\text { (ATM) }\end{array}$ & $\begin{array}{l}\text { A focal inflammatory disorder of the spinal cord } \\
\text { resulting in motor, sensory and autonomic dysfunction }\end{array}$ \\
\hline Schilder's Disease & $\begin{array}{l}\text { A sub-acute demyelinating disorder characterized by } \\
\text { bilateral large and vaguely symmetrical lesions }\end{array}$ \\
\hline $\begin{array}{l}\text { Paediatric Multiple Sclerosis } \\
\text { (MS) }\end{array}$ & $\begin{array}{l}\text { A clinical syndrome of multiple clinical demyelinating } \\
\text { events involving } \\
\text { more than one area of the central nervous system with } \\
\text { dissemination in time and space on imaging* }\end{array}$ \\
\hline $\begin{array}{l}\text { Clinically Isolated Syndromes } \\
\text { (CIS) }\end{array}$ & $\begin{array}{c}\text { A first acute clinical episode of } \\
\text { CNS symptoms (without encephalopathy) with a } \\
\text { presumed inflammatory demyelinating cause; for } \\
\text { which there is no prior history of a demyelinating } \\
\text { event }\end{array}$ \\
\hline
\end{tabular}

*Important caveats in the definition of Paediatric MS put forward by the study group include:

1. The combination of an abnormal CSF (presence of Oligoclonal bands or an elevated IgG index) and two lesions on the MRI, of which one must be in the brain, can also meet dissemination in space criteria.

2. The MRI can meet the dissemination in space criteria if it shows 3 of the following 4 criteria (1) nine or more white matter lesions or one gadolinium enhancing lesion, 2) three or more periventricular lesions, 3) one juxta-cortical lesion, 4) an infra-tentorial lesion.

3. MRI can be used to satisfy criteria for dissemination in time following the initial clinical event, even in the absence of a new clinical event if new T2 or gadolinium enhancing lesions develop within 3 months of the initial clinical event.

4. A second non-ADEM event in a patient is insufficient to make the diagnosis of paediatric MS if the first event meets the criteria for ADEM. MS can only be diagnosed if there is further evidence of dissemination in time on the MRI (new T2 lesions > 3months since the second event) or a new clinical event (> 3months since the second event).

Table 1. Definitions of Acquired Demyelinating Disorders (Adapted from Krupp et al 2007) 
as magnetization transfer imaging, magnetic resonance spectroscopy, and diffusion tensor imaging, provide quantitative information about the extent of damage that occurs in the white matter.

1H magnetic resonance spectroscopy (MRS) is a valuable technique to non-invasively acquire in-vivo information about biochemical processes in patients with neurologic disorders. MRS measures N-acetyl-aspartate (NAA), total creatine, choline-containing compounds, and lactate. NAA has been considered a marker of neuronal integrity, whereas the levels of choline and lactate are indicative of cell membrane turnover and anaerobic glycolysis (Bizzi et al., 2001). NAA is located almost exclusively in neurons and neuronal processes and thus provides information about neuronal integrity (De Stefano et al., 1995).

MRS studies on patients with white matter disorders have shown reduction in NAA in areas that appear normal on conventional MRI studies suggesting that a significant amount of axonal damage is present in these patients (Arnold et al., 1990; van Der Knaap et al., 1992). Abnormalities in NAA on MRS have also shown a correlation with long term functional outcomes. The author suggests that the extent of axonal damage rather than demyelination may be more reliable in monitoring disease evolution in primary white matter disorders (De Stefano et al., 2000).

Diffusion-weighted MR imaging (DWI) provides further information that may not be apparent on conventional MR images. Engelbrecht et al showed that diffusion restriction precedes brain myelination and is further increased during myelination (Engelbrecht $e t$ al., 2002).

\section{Acquired Demyelinating Encephalomyelitis (ADEM)}

ADEM initially described by Lucas (1790) is characterized by acute onset of diffuse neurological signs with multi-focal white matter involvement. In 1931 a series of case studies was reported in The Lancet. McAlpine described 3 sets of patients with ADEM: -post-vaccination, post-infectious, and those with spontaneous occurring disease. The International Paediatric MS study group further defined ADEM (see Table 1).

\subsection{Pathogenesis}

The aetiology of ADEM is not completely understood. The pathogenesis is thought to be auto-immune mediated. The seasonal distribution and high rate of antecedent infections (Dale et al., 2000; Murthy et al., 2002; Govender et al., 2010) reported in ADEM suggest a link to an infectious aetiology. Infectious diseases are common in childhood however the rate of preceding infection reported in these series exceed the rate of childhood infectious diseases described (30-50\%). The auto-immune reaction is thought to be on the basis of molecular mimicry. The offending infection serves as an antigenic trigger and shares epitopes with various autoantigens of myelin such as myelin basic protein, proteolipid protein, and myelin oligodendrocyte protein (Alvord et al., 1987). This theory shares many similarities with experimental allergic encephalitis. A second theory is that the antigenic trigger activates $T$ cells which cross the blood-brain barrier and react against similar myelin epitopes. ADEM was associated with the class II alleles HLA-DRB1*01 and HLA-DRB*03 in a Russian study (Idrissova et al., 2003). Pathological studies of children 
with ADEM showed that peripheral and cerebrospinal lymphocytes have increased reactivity to myelin basic protein (Lisak and Zweiman, 1977). Viral infections described in the context of ADEM include Herpes Simplex Virus-1, Cytomegalovirus (CMV), HIV (Human Immunodeficiency virus), Measles, Mumps, Rubella, Ebsteinne Barre Virus (EBV) and Varicella Zoster Virus (VZV). ADEM occurs after one of every 1000 cases of measles, with a fatality rate of $20 \%$ (Tselis and Lisak, 1998). Bacterial antigens implicated include Mycoplasma, Campylobacter, Streptococci and Borrelia Burgdofferi. Dale et al. described a subgroup of ADEM associated with Group A $\beta$ hemolytic streptococcus, abnormal basal ganglia imaging and elevated antibasal ganglia antibodies (Dale et al., 2001). Some studies fail to identify the agent responsible for the pre-demyelinating infection (Murthy et al., 2002). The authors postulate that the inciting agents are uncommon or unusual organisms that can not be identified by routine laboratory testing. Vaccines, specifically the influenza, rabies and smallpox vaccines have also been reported to precipitate ADEM (Saito et al., 1998). Post-vaccination ADEM is thought to be the result of immune mediated mechanisms rather than the cyto-pathic effects of the virus. ADEM is reported after the administration of drugs such as sulfonamides and streptomycin, further supporting an immunological basis of the pathogenesis.

\subsection{Epidemiology}

There are few epidemiological studies of ADEM in children. Prevalence studies are also complicated by the use of inconsistent case-definitions of ADEM. The estimated incidence in California is $0.4 / 100,000$ population per year (Leake et al., 2004) and in Canada is 0.2/100,000 per year (Banwell et al., 2009). The mean age of presentation of ADEM in children ranges from 5-8 years (Hynson et al., 2001; Tenembaum et al., 2007). There is no specific ethnic distribution (Leake et al., 2004). Some studies indicate a slight male predominance (Murthy et al., 2002; Tenembaum et al., 2007). Prevalence in resource poor countries would be expected to be higher because of the significant frequency of childhood infections. However it is probably under-estimated because of limited access to health care facilities and MRI facilities.

\subsection{Clinical presentation}

ADEM has a wide clinical spectrum of presentation. The hallmark of the disease is an acute presentation of multifocal neurological signs with encephalopathy consistent with diffuse brain involvement usually following a viral infection or immunization. However, events may range from sub-clinical episodes diagnosed by MRI showing mult-ifocal white matter lesions, to a more fulminant presentation with seizures and encephalopathy. Seizures are reported to be more common in children compared to adults with ADEM (Tenembaum et al., 2007). Fever and meningism are also common in ADEM prompting treatment for meningo-encephalitis in the initial management (Dale et al., 2000). Multi-focal neurological signs are pathognomic for ADEM and include hemiparesis, paraparesis, cranial nerve involvement and ataxia. Atypical presentations include concomitant peripheral nervous system involvement (Kinoshita et al., 1996), presentation as an isolated acute psychotic episode (Moscovich et al., 1995) or with an extra-pyramidal syndrome (dystonia and behaviour disturbances) (Dale et al., 2001). 


\subsection{Laboratory investigations}

In the absence of specific biological markers diagnosis is based on a combination of historical features, clinical and MRI characteristics. Other investigations are usually done to exclude other differential diagnosis (e.g. meningitis, metabolic encephalopathies). In resource poor settings where the burden of disease is predominantly infectious illnesses and because of the overlap of symptoms, infectious aetiologies must be excluded first. Peripheral blood leucocytosis is documented in ADEM (Jacobs et al., 1994). CSF studies in ADEM are usually abnormal (in $>67 \%$ of cases), typically showing a moderate pleocytosis with an elevated protein content (Miller et al., 1956; Govender et al., 2010). CSF Oligoclonal bands synthesis may occur in ADEM; however this tends to disappear when the patient recovers.

Electrophysiological studies have limited value in ADEM. Slow-wave abnormalities on electro-encephalogram are compatible with an encephalopathic state (Dale et al., 2000). The spindle coma pattern has been described in a child with post measles ADEM (Bortone et al., 1996). Visual evoked potentials though are useful in detecting asymptomatic optic tract lesions (Dale et al., 2000).

\subsection{Neuro-imaging}

MRI is the investigation of choice. Since CT is often non-diagnostic for white matter lesions in patients with ADEM, this study is often normal or shows non-specific hypo-densities in the white matter.

Lesions are most easily recognized on T2 weighted (T2WI) and FLAIR MRI sequences. T2WI are more sensitive than T1 weighted images (T1WI) in detecting lesions (Sheldon et al., 1985). T1WI shows hypo-intense lesions. The lesions of ADEM are multi-focal and often do not correlate with clinical signs. Lesions tend to involve the cerebellum, the cerebral cortex and brainstem (Figure $\mathbf{1} \mathbf{~ a - g ) . ~ T h e y ~ u s u a l l y ~ i n v o l v e ~ t h e ~ s u b - c o r t i c a l , ~ c e n t r a l ~ a n d ~}$ periventricular white matter. Lesions are typically hyper-intense, patchy, asymmetric and ill-defined. Diffusion-weighted imaging (DWI) and apparent diffusion co-efficient (ADC) maps may be helpful to prognosticate outcome. Low ADC values and restricted diffusion on DWI may suggest a worse outcome as this may indicate permanent tissue damage (Barkovich., 2007). A case study of ADEM with MRS reported reduced NAA and an elevation of choline and lactate (Gabis et al., 2004). These authors suggest a place for H MRS studies in longitudinal follow-up studies of ADEM to assess the response to immunomodulating therapies. Deep grey matter lesions in the thalami and basal ganglia have also been described (Baum et al., 1994; Govender et al., 2010) (Figure 2a-e). Lesions in the corpus callosum are uncommon and considered atypical for ADEM (Figure 3). Contrast enhancement of lesions post gadolinium administration indicates activity of the lesions (Figure 4). This correlates with the pathological finding of inflammation and demyelination in experimental allergic encephalitis. Non-enhancing and partially enhancing lesions in the presence of enhancing lesions have been described in ADEM and are thought to be because of lesions of differing ages and the evolution of the disease over several weeks (Schwaz et al., 2001; Govender et al., 2010).

Concomitant spinal cord lesions have been described in ADEM (Hynson et al., 2001; Murthy et al., 2002; , Govender et al., 2010) (Figure 5a,b). Spinal cord lesions in ADEM typically have ill-defined margins, extend over multiple vertebral segments, are thoracic in location and result in mild cord expansion (Singh et al., 2002). 


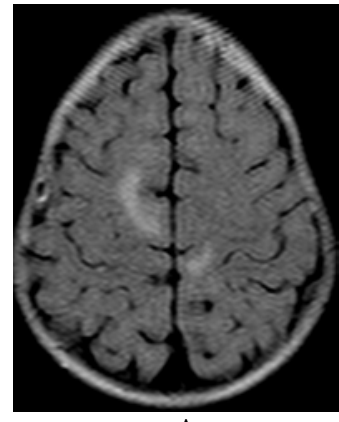

A

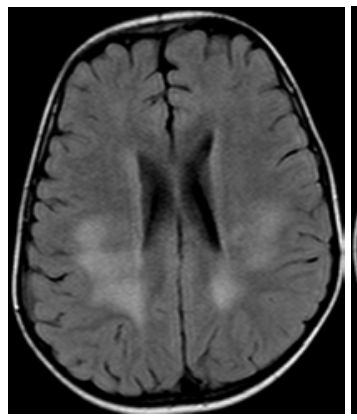

C

$\mathrm{E}$

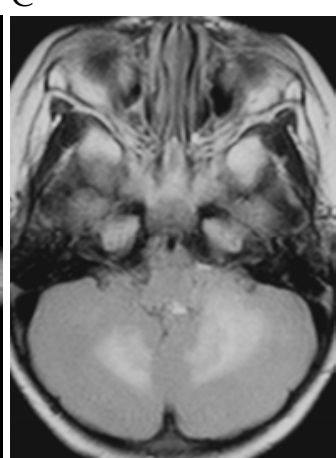

$\mathrm{F}$

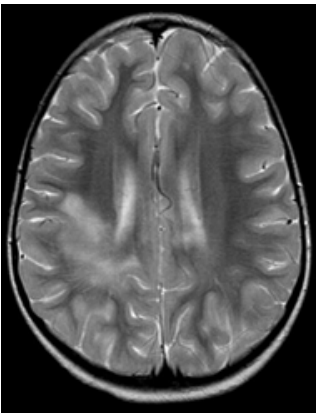

B

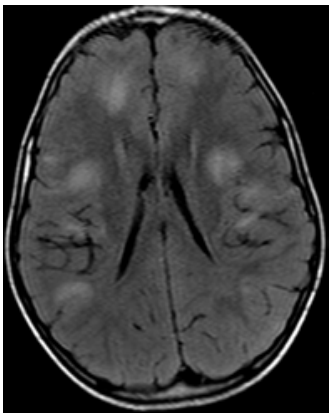

$\mathrm{D}$

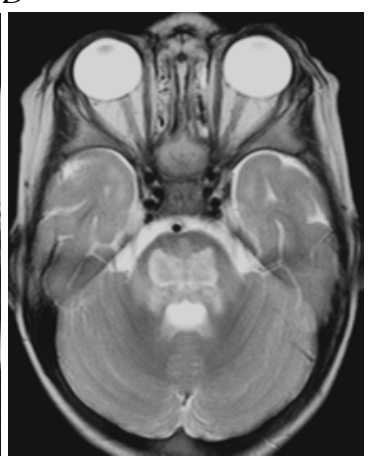

G

Fig. 1. A - Flair axial MRI demonstrating bilateral asymmetrical cortex and sub-cortical white matter high signal intensities consistent with ADEM. B- T2 axial MRI demonstrating right ill-defined peritrigonal white matter high signal intensity lesion consistent with ADEM. C- Flair axial MRI demonstrating bilateral, fairly symmetrical high signal intensities in the posterior white matter consistent with ADEM. D - Flair axial MRI demonstrating bilateral asymmetrical high signal intensity lesions in the sub-cortical and deep white matter consistent with ADEM. E- Flair axial MRI demonstrating bilateral asymmetrical high signal intensity lesions in the cortex and sub-cortical and deep white matter consistent with ADEM. F - Flair axial MRI demonstrating hyper-intense lesions in the brachium ponti consistent with ADEM. G - T2 axial MRI of the brain demonstrating large hyper-intense pontine lesion with surrounding oedema 


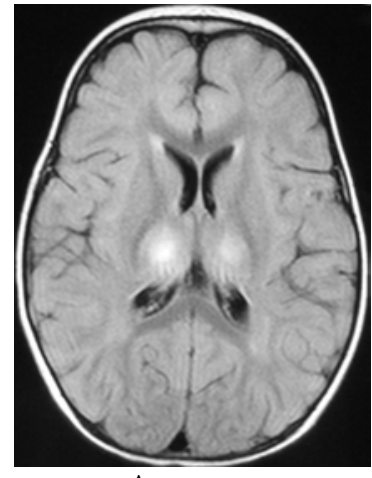

A

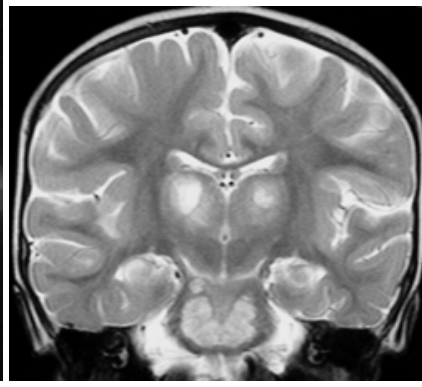

B

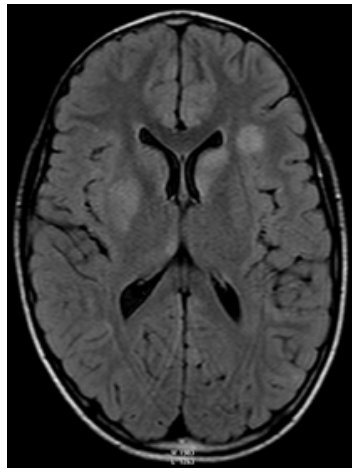

C

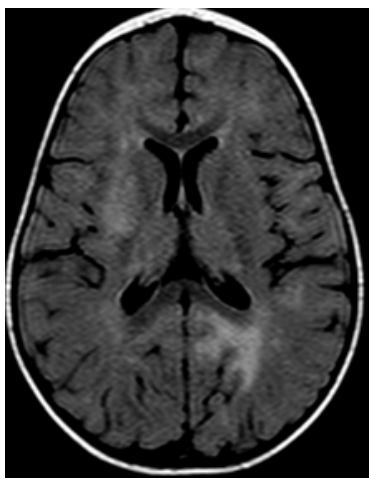

$\mathrm{D}$

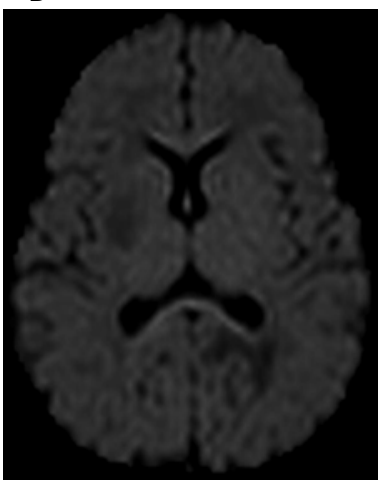

$\mathrm{E}$

Fig. 2. A- Flair axial MRI of the brain demonstrating bilateral symmetrical hyper-intense thalamic lesions. B- T2 coronal MRI of the brain demonstrating bilateral symmetrical rounded hyper-intense thalamic lesions as well as a large hyper-intense pontine lesion. CFlair axial MRI demonstrating bilateral high signal intensity lesions in the basal ganglia and deep white matter on the left consistent with ADEM. D- Flair axial MRI demonstrating asymmetrical basal ganglia and white matter high signal intensities consistent with ADEM. E- DWI of 2D shows no evidence of restricted diffusion.

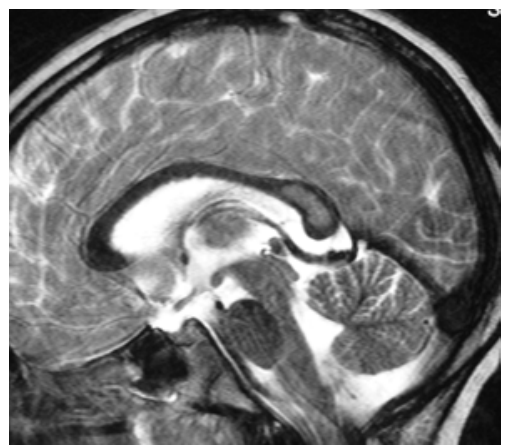

Fig. 3. T2 sagittal midline brain MRI demonstrating a well-defined rounded lesion in the splenium of the corpus callosum, which is unusual for ADEM. 


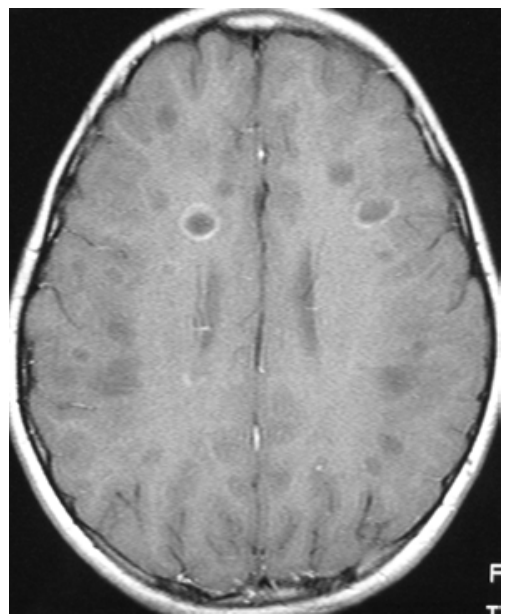

Fig. 4. T1 with contrast axial MRI demonstrating multiple hypo-intense white matter lesions of varying sizes, some with ring enhancement. This patient was diagnosed with ADEM.

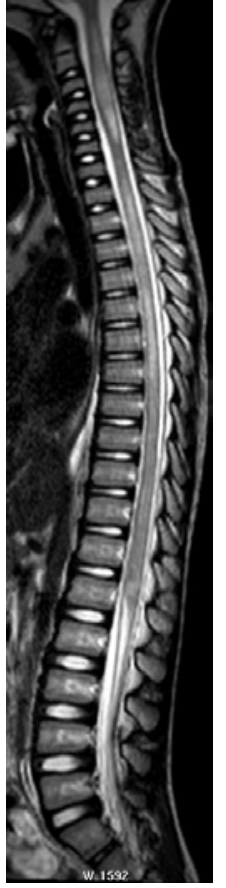

A

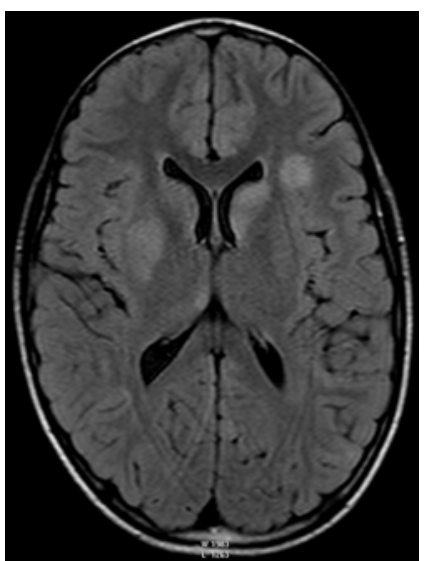

B

Fig. 5. A- T2 sagittal MRI of the cord showing diffuse abnormal high signal intensity throughout the cord with cord expansion in the cervical region. There was no associated enhancement. This together with the brain lesions seen in 5B is consistent with ADEM. BFlair axial MRI demonstrating bilateral high signal intensity lesions in the basal ganglia and deep white matter on the left consistent with ADEM. 


\subsection{Treatment}

There are no standard treatment protocols as there are insufficient large scale studies to form consensus for optimal management. Supportive care (e.g. respiratory support for patients with brainstem involvement, anti-epileptics for seizure control) in the acute phase is vital.

Therapies recommended are mainly immunomodulating agents targeting the immunebased mechanism of the disease. Corticosteroids are considered the mainstay of treatment based on the rapid improvement in symptoms following therapy (Straub et al., 1997; , Tenembaum et al., 2007). However widely varying doses, formulations, duration of therapy and tapering have been reported with corticosteroid use (Hynson et al., 2001; Murthy et al., 2002; Tenembaum et al., 2007; Govender et al., 2010). A single study reported worse outcomes in patients who received corticosteroids (Boe et al., 1965). Methylprednisone, dexamethasone and ACTH are used. Most reports in paediatric patients have used IV methylprednisolone (10 to $30 \mathrm{mg} / \mathrm{kg} /$ day) or dexamethasone $(1 \mathrm{mg} / \mathrm{kg})$ for 3 to 5 days (Dale et al., 2000; Hyson et al 2001; Tenembaum et al 2002; Govender et al., 2010) followed by a taper for 4 to 6 weeks with full recovery reported in 50 to $80 \%$ of patients. In resource poor countries high dose corticosteroids must be used with caution and only commenced once commonly occurring infections like tuberculosis and cytomegalovirus (CMV) are excluded. Outcomes on efficacy of corticosteroid treatment are mainly compared to historical controls. Worse outcomes are linked to shorter duration of treatment (Tenembaum et al., 2007). Other treatment modalities suggested include intravenous immunoglobulin, plasmapheresis and glatiramer acetate (Abramsky et al., 1977; Stricker et al., 1992; Finsterer et al., 1998). There is some evidence to suggest that patients may respond to a combination of methylprednisolone and immunoglobulin if they fail to respond to either separately (Straussberg et al., 2001).

\subsection{Prognosis}

ADEM is by definition a monophasic illness (variants are discussed in Section 4.8). Mortality during the post-measles ADEM period in the 1950's was reported as 10-30\% (Johnson et al., 1985). At follow-up, approximately $60-80 \%$ of children have no neurologic deficits (Menge et al., 2007). This study also reports a mortality rate of $5 \%$. The extent and site of lesions on the initial MRI do not predict the clinical outcome. Motor deficits persist in 8-30\% (Dale et al., 2000; Tenembaum et al., 2007) of patients and include paraparesis, hemiparesis and ataxia. Neuro-cognitive deficits are also documented post ADEM (Hahn et al., 2003; Jacobs et al., 2004). These include deficits in short term memory, verbal processing skills and complex attention. Patient with early onset ADEM (<5year of age) were also more likely to have cognitive deficits and behaviour problems (Kumar et al., 1998). Follow-up MRI's showed complete or partial resolution of abnormalities in the majority of cases (Kesslering et al., 1990; Dale et al., 2000; Tenembaum et al 2007; Govender et al., 2010). However, residual gliosis and demyelination persist in some patients (Kesselring et al., 1990). Clinical as well as imaging follow-up (at least 3 months later) (Figure 6) is important to monitor for evolution to MS. Risk factors for relapse are discussed in greater detail in Section 10.

\subsection{Variants of ADEM}

Definitions for Recurrent and Multi-phasic ADEM are described in Table 1.

Acute Hemorrhagic Leukoencephalitis is a rare, hyper-acute form of ADEM with a mortality rate of about 70\% (Davies et al., 2006). Pathological studies show a necrotizing vasculitis 
with haemorrhage, oedema and a neutrophilic infiltration (Stone and Hawkins, 2007). Seventy percent of survivors have neurological deficits (Stone and Hawkins, 2007).

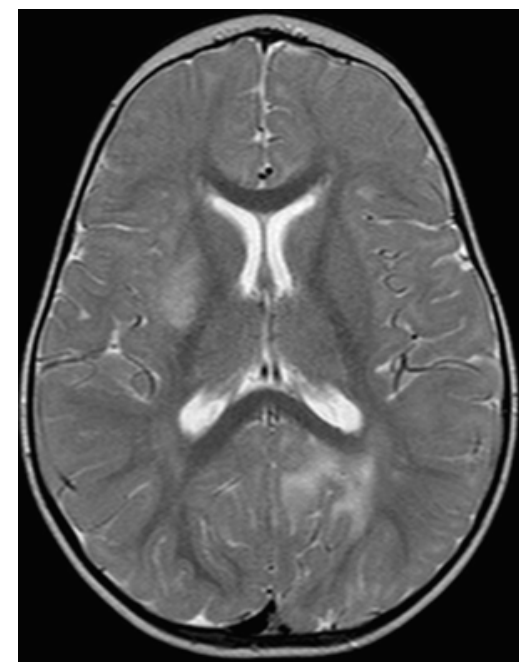

A

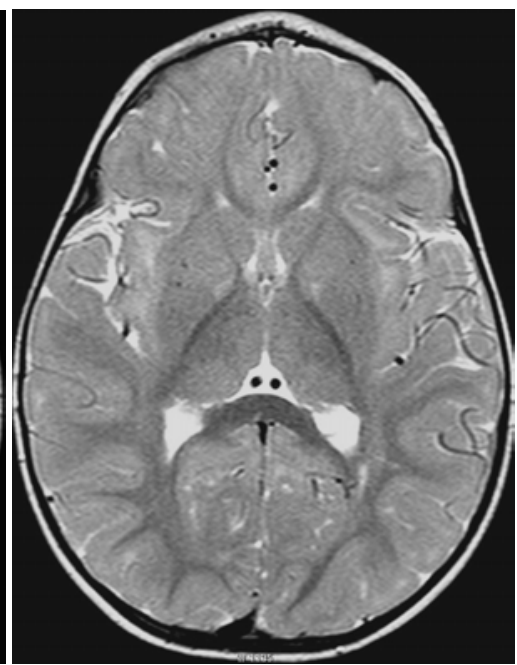

B

Fig. 6. A- T2 axial MRI demonstrating asymmetrical basal ganglia and white matter high signal intensities consistent with ADEM. B- T2 axial MRI in same patient at 3 months followup showing resolution of lesions.

\section{Transverse myelitis}

\subsection{Epidemiology}

Acute Transverse myelitis (ATM) is a focal inflammatory disorder of the spinal cord resulting in motor, sensory and autonomic dysfunction with evidence of inflammation on CSF or MRI studies. The initial definition was proposed by the Transverse Myelitis Consortium Working Group in 2002 and refined by the more recent consensus definitions for paediatric demyelinating disease (Krupp et al., 2007). The incidence is reported as 1- 8 per million people per year (Berman et al., 1981). There are no gender or ethnic differences in the prevalence of ATM (Berman et al., 1981). ATM is often difficult to distinguish clinically from ischaemic cord lesions, fibro-cartilagenous emboli or traumatic spinal cord lesions. ATM is also an important differential diagnosis for acute flaccid paralysis in childhood.

\subsection{Pathogenesis}

The aetiology of ATM is thought to be immune-mediated. In $30-60 \%$ of patients ATM is para-infectious (Jeffrey et al., 1993; Kalra et al., 2009). Molecular mimicry and super-antigen mediated mechanisms have been postulated (Kaplin et al., 2005). Positive anti-GM1 antibodies following Campylobacter and CMV infections have been implicated in the aetiopathogenesis. Neuromyelitis optica-immunoglobulin G is an aquaporin-4-specific water channel antibody, which has been associated with neuromyelitis optica and longitudinally extensive transverse myelitis in adults (Lennon et al., 2004). This is discussed further in Section 6. 


\subsection{Clinical presentation}

Clinical presentation is that of acute or sub-acute onset of bilateral spinal cord dysfunction (that may be asymmetrical) with associated sphincter dysfunction and pain. A sensory level may not be easily elicitable in the paediatric population. The clinical features depend on the location of the lesion. High cervical cord lesions can present with respiratory failure. The thoracic segment is the commonest site of cord involvement in ATM (Kneubusch et al., 1998).

\subsection{Investigations}

Initial evaluation of a patient with an evolving myelopathy must include a gadolinium enhanced MRI of the spine to exclude a compressive myelopathy. If there is no evidence of a compressive lesion a lumbar puncture should be performed. CSF pleocytosis and an elevated protein (IgG index) on the CSF support a diagnosis of ATM. Brain MRI and eye examination with visual evoked potentials are recommended to exclude demyelination in other parts of the neuro-axis.

Other investigations recommended include para-infectious markers- EBV, VZV, CMV, Herpes Simplex virus serology and stool for campylobacter cultures. If there are signs of a systemic inflammatory disorder, auto-immune screens and serum angiotensin converting enzyme levels should be performed to exclude other causes of an acute myelopathy (e.g. vasculitides).

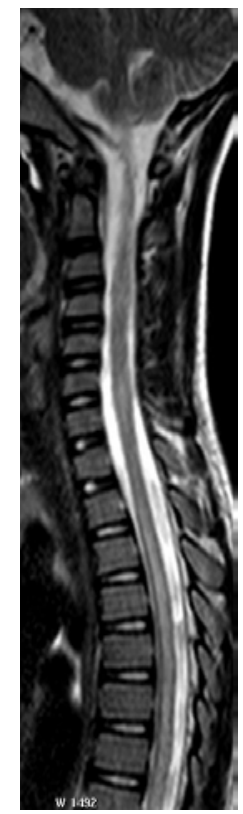

A

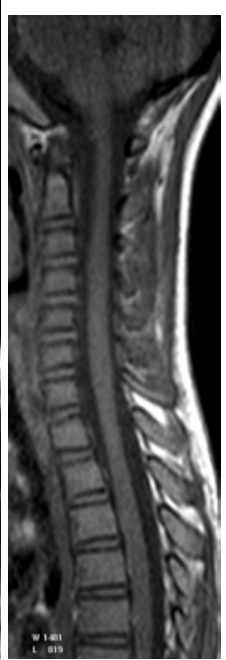

B

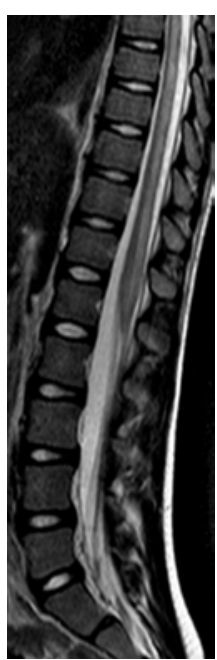

C

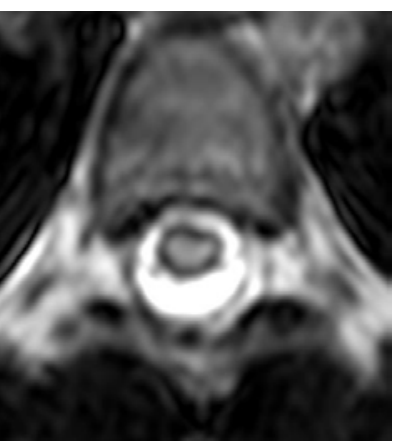

$\mathrm{D}$

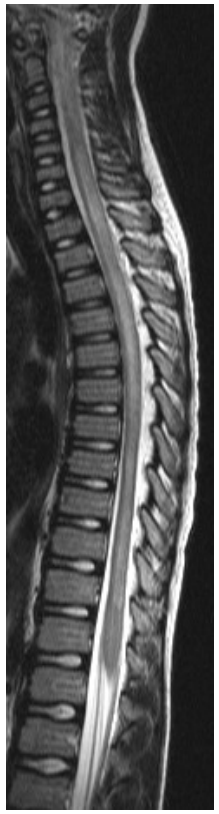

E

Fig. 7. A- T2 sagittal MRI of the cord showing diffuse abnormal increased signal intensity consistent with transverse myelitis. B- T1 sagittal MRI of the cord showing no abnormal signal intensity. There was no contrast enhancement. C- T2 sagittal MRI of the distal cord showing diffuse abnormal increased signal intensity consistent with transverse myelitis. DT2 axial MRI of the cord showing abnormal increased signal intensity consistent with transverse myelitis. E- T2 sagittal MRI of the cord showing diffuse abnormal increased signal intensity and cord swelling consistent with transverse myelitis. 


\subsection{Neuro-imaging}

MRI of the spinal cord usually shows nonspecific localized hyper-intense signal on T2WI sequences with, in some cases, segmental cord enlargement and/or focal enhancement (Figure 7 a-e). Acute partial transverse myelitis described in adults is characterized by MRI lesions that are asymmetrically placed and spanning fewer than 2 vertebral segments in length; these patients have been found to have a greater risk of progression to multiple sclerosis (Ford et al., 1992). Longitudinally extensive myelitis (spanning $>3$ vertebral segments) is shown to have a lower risk of progression to MS in adults (Pittock et al, 2006). Lesions of ATM in children are typically longitudinal, demonstrate rim enhancement and are centrally located.

\subsection{Treatment}

Previous case series did not demonstrate any benefit from the use of low dose corticosteroids (Dunn et al., 1986; Adams et al., 1990). Recent reports demonstrate the benefit of high dose corticosteroids (10-30mg/ $\mathrm{kg}$ per day for 3-5 days) on recovery (Defrense et al., 2001; Sebire et al., 1997). Compared to historical controls patients treated with steroids walked independently sooner. If there is no clinical response to steroids within 5-7 days plasma exchange was used as adjunctive therapy in isolated case reports. Supportive measures include respiratory support and early management of a neuropathic bladder.

\subsection{Prognosis}

Various studies have looked at prognostic indicators for ATM. Jain et al. (1983) described backache at onset, acute course (within hours), spinal shock and a cervical sensory level as poor prognostic features. Other studies did not demonstrate this (Govender et al., 2010). Early recovery (within one week of presentation), age less than 10 years at presentation and lumbosacral spinal level on clinical assessment were significant predictors of a good outcome (De Goede et al., 2010). The extent of lesions on MRI has not shown consistent correlation with outcome (Pradhan et al., 1997; Adronikou et al., 2003). Berman et al's series (1987) described more than one-third of the patients with ATM making a good recovery; in one-third of patients recovery was only fair; 14 patients failed to improve and 3 demised.

In the series by Dunne et al (1986) that assessed the risk of progression to multiple sclerosis in children with ATM, definite evidence of multiple sclerosis did not develop in any of the patients. In the series by Pidcock et al of the 47 children with acute transverse myelitis, 2 experienced recurrent transverse myelitis, 1 was diagnosed with neuromyelitis optica, and 1 developed multiple sclerosis on follow-up (Pidcock et al., 2007).

\section{Neuromyelitis Optica (NMO)}

The association between myelitis and optic problems was first described in 1870 by Thomas Clifford Allbutt (Murray, 2005). In 1894 Eugene Devic described 16 patients with visual impairment who developed paraparesis, sensory deficits and sphincter dysfunction within weeks. They recognized that these symptoms were the result of inflammation of the optic nerve and spinal cord. NMO is a recurrent demyelinating disorder affecting the optic nerves and the spinal cord. Modifications to the definition of NMO in 2005 incorporated the inclusion of patients with brain lesions, and included the NMO-IgG antibody as a confirmatory test. 
The Mayo Clinic proposed a revised set of criteria in 2006. The new guidelines for diagnosis requires both absolute criteria and two of the three supportive criteria to be present to make a diagnosis of NMO (Wingerchuck et al., 2006).

Absolute criteria:

1. Optic neuritis

2. Acute myelitis

Supportive criteria:

1. Brain MRI not meeting criteria for MS at disease onset

2. Spinal cord MRI showing contiguous T2-weighted signal abnormality extending over 3 or more vertebral segments, indicating a relatively large lesion in the spinal cord

3. NMO-IgG seropositive status.

The association of NMO with the serum autoantibody marker NMO-IgG was reported in 2004 (Lennon et al., 2004). NMO-IgG is 73\% sensitive and 91\% specific for distinguishing NMO from classical MS. The new diagnostic criteria allows for the diagnosis of NMO in patients who are NMO-IgG antibody negative. NMO antibodies play a key role in the pathogenesis. These antibodies are directed against the aquaporin-4- receptors located in the cell membrane of astrocytes (Pearce, 2005). Aquaporin-4 is the most abundant channel facilitating water transport across membranes in the brain. NMO-IgG is also detected more commonly in patients with NMO symptoms who have clinical or serological evidence for SLE than in those who do not (McAdam et al., 2002).

\subsection{Clinical characteristics}

Clinical characteristics include painful visual loss, weakness, sphincter dysfunction and sensory deficits. Loss of red color vision, a relative afferent pupillary defect and visual field defects are other features of optic neuritis in children. Other complications such as ataxia and respiratory failure result from extension of cervical cord lesions into the brainstem.

\subsection{Investigations}

Diagnostic evaluation includes an MRI of the brain. During acute optic neuritis attacks, an orbital MRI may identify optic nerve gadolinium-enhancement. MRI of the brain is usually normal. However, brain lesions located in the hypothalamus, brainstem, and periventricular areas have been described in children who have typical features of NMO (Pittock et al., 2005). These are considered to be the aquaporin- 4 rich areas of the brain.

Patients with signs of myelitis should have a spinal MRI with contrast. The lesions are typically longitudinally extensive, centrally based in the cord and extend over three or more vertebral segments. All patients should have a serological test for the NMO-IgG antibody. A negative test however does not exclude the diagnosis. CSF pleocytosis also supports the diagnosis. In patients with longitudinal myelitis and no visual symptoms, visual evoked potentials can sometimes detect asymptomatic visual pathway dysfunction.

\subsection{Treatment}

The recommended treatment for acute attacks of myelitis or optic neuritis is high dose methylprednisone. Prophylactic long-term immunosuppression is recommended for established NMO and patients who have a single attack of myelitis and are NMO-IgG positive (Wingerchuck et al., 2005). There are no efficacious preventative therapies demonstrated by controlled trials in NMO. Intravenous immunoglobulin is an alternative for patients who do not respond to corticosteroids. 
Characteristics of NMO that help to distinguish it from classical MS include:

- Prominent CSF pleocytosis (more than $50 \mathrm{WBC}$ ) with a polymorphonuclear cell predominance (Mandler et al., 1993; O Riordan et al., 1996)

- Lower frequency of CSF oligoclonal banding (15-30\% in NMO compared to 85\% in MS)

- Bilateral symmetrical optic neuritis

- At disease onset, the brain MRI scan is normal or reveals nonspecific white matter lesions

- $\quad$ MRI of the spinal cord showing longitudinally extensive, central lesions (MS lesions are more peripherally located in the cord and extend over one to two segments in length)

\section{Schilder's disease/myelinoclastic diffuse sclerosis}

This disorder was initially described by Schilder in 1912 and later clarified by Poser (1992). There are further reported cases of solitary, large plaque like lesions, which were histologically confirmed to be foci of demyelination (Kumar et al., 1998; Gutling and Landis, 1998). The aetiology is unclear; however an association with tuberculosis was described in 3 South African children (Pretorius et al., 1998). Schilder's Disease occurs predominantly in children (peak age 5-14 years) (Afifi et al., 1994).

The Poser criteria (1992) for diagnosis are:

- $\quad$ one or two roughly symmetrical large plaques (greater than $2 \mathrm{~cm}$ diameter)

- pathological analysis is consistent with sub-acute or chronic myelinoclastic diffuse sclerosis

- $\quad$ adrenoleukodystrophy and peripheral nervous system involvement must be excluded.

\subsection{Clinical presentation}

The clinical presentation is non-specific and includes neuroregression, seizures, ataxia or signs of raised intra-cranial pressure.

\subsection{Neuro-imaging}

The lesions of Schilder's Disease are typically large and plaque-like and have also been termed tumefactive demyelination. MRI is the most accurate modality of delineating the lesions that are often confused with brain neoplasms or abscesses. Making the distinction between demyelination and infection/malignancies early is important to prevent unnecessary surgical procedures and toxic therapies like radiation and chemotherapy (McAdam et al., 2002). MRI studies demonstrate 1 or 2 large confluent lesions in the deep white matter, usually the centrum semiovale (Figure 8 a-f). Lesions are at least $2 \mathrm{~cm}$ in size in 2 of 3 dimensions. No additional lesions should be observed on imaging of the brain or spinal cord- this would suggest MS or ADEM. On T1WI, tumefactive demyelination lesions reveal a hypo-intense central area with a thick surrounding band of moderately increased intensity. Lesions are centrally hyper-intense on T2WI. Enhancement, when present, is incomplete. The lesions are characterized by enhancement limited to one side of the lesion; usually the rim facing the lateral ventricles (McAdam et al., 2007). Demyelination can be distinguished from other ring enhancing lesions (brain abscesses, tumors, parasitic infections) by the presence of other demyelinating plaques elsewhere in the central nervous system. 

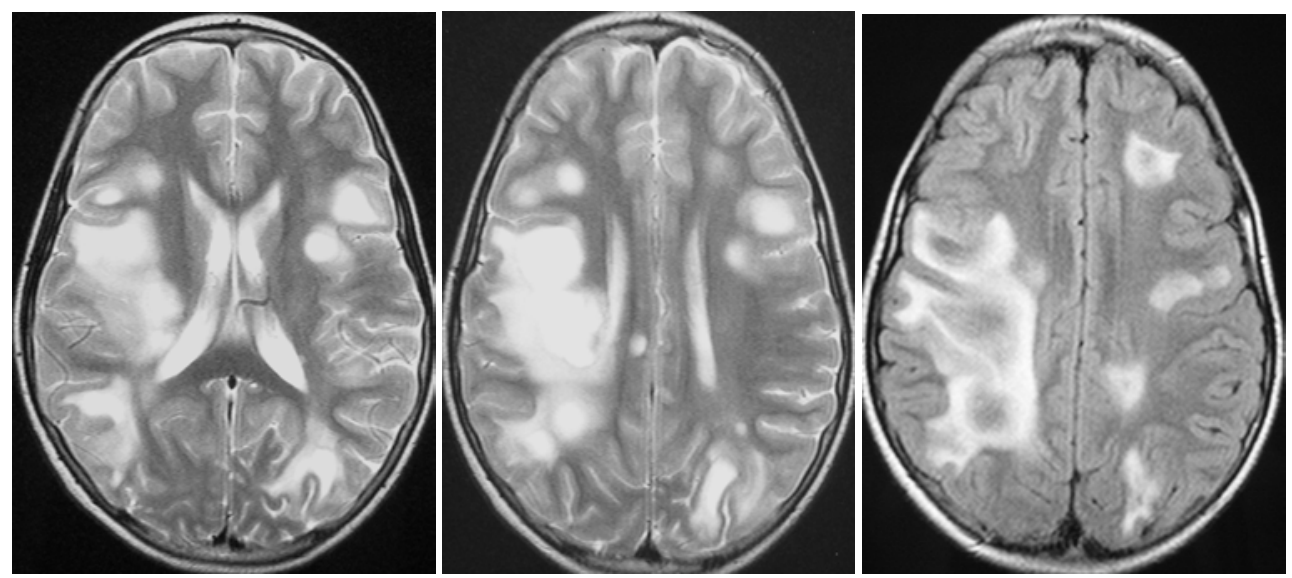

A

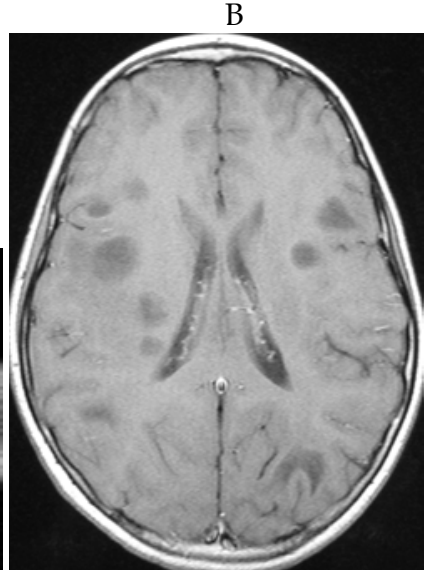

$\mathrm{E}$

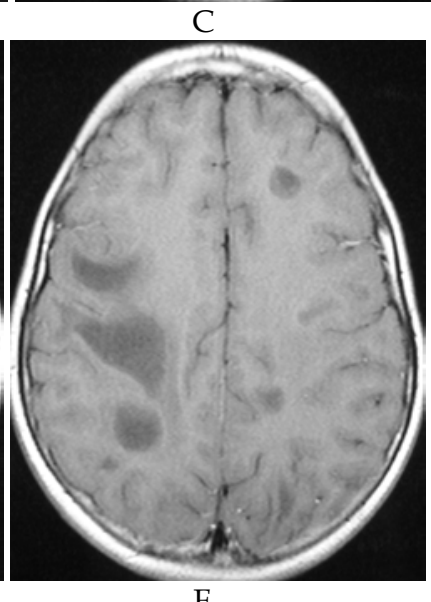

$\mathrm{F}$

Fig. 8. A \& B - T2 axial MRI demonstrating multiple well-defined hyper-intense white matter foci surrounded by more ill-defined areas of increased white matter signal intensity consistent with Schilder's Disease. C- Flair axial MRI demonstrating multiple hyper-intense lesions of varying sizes within the white matter with some areas of suppression within the plaques consistent with Schilder's Disease. D- Flair parasagittal MRI demonstrating large flame- shaped white matter plaque with some areas of suppression within the lesions consistent with Schilder's Disease. E \& F- T1 with contrast axial MRI demonstrating multiple non- enhancing hypo-intense lesions of varying shapes and sizes within the white matter.

Other supportive diagnostic tests include an elevated CSF protein and an elevation of CSF IgG in 50-60\% of patients with Schilder's Disease. Many patients with a large ring enhancing lesion will have a brain biopsy mainly to exclude other disorders.

\subsection{Treatment}

The treatment of choice is high dose intravenous corticosteroids. A rapid clinical and radiological response to high dose corticosteroids favors the diagnosis of demyelination. 


\section{Multiple Sclerosis (MS)}

MS is defined in Table 1 (Krupp et al., 2007). MS in children is likely an under-recognized phenomenon that poses a unique set of challenges in terms of diagnosis and management. Early accurate diagnosis of MS is vital to facilitate early institution of disease modifying agents.

\subsection{Epidemiology}

Childhood onset MS is an uncommon entity however, an estimated 2- 5\% of patients with MS have onset of symptoms of MS before 16 years of age (Duquette et al., 1987; Boiko et al., 2002). The youngest reported patient with MS presented at 10 months of age. This was an indigenous African child who died at 6 years of age after 11 episodes of relapsing neurological symptoms (Shaw and Alvord, 1987). Similar to adult studies, a female preponderance is reported for MS in adolescence (Duquette et al., 1987; Govender et al., 2010). However there is no gender predilection in children presenting with MS under 6 years of age (Banwell et al., 2007).

A crude period prevalence for patients of European ancestry was 25.63 per 100000 and for patients of indigenous African descent was 0.22 per 100000 (Bhigjee et al., 2007). Adult studies have described a more severe clinical and radiological phenotype in patients of African indigenous ancestry compared to patients of European ancestry (Kaufmann et al., 2003; Bhigjee et al., 2007). A retrospective single centre analysis showed a significantly higher relapse-rate in African-American children, compared with whites, suggesting a more aggressive disease course in the former group (Boster et al., 2009).

\subsection{Pathogenesis}

Genetic and environmental factors are implicated in the aetiology of MS. Twin studies show a $20-30 \%$ higher risk of disease in monozygotic twins compared to dizygotic twins. Allelic variation in the MHC class II region exerts the single strongest effect on genetic risk (Ramgopalan SV et al., 2009). The HLA DR1B is the gene marker associated with higher risk of MS (Ness et al., 2007). Alleles of IL2RA, IL7RA (Hafler et al., 2007), the ecotropic viral integration site 5 (EVI5) (Hoppenbrouwers et al., 2008) and kinesin family member 1B (KIF1B) genes (Aulchenko et al., 2008) have recently been shown to increase susceptibility to MS.

Epidemiological studies implicate environmental factors such as geographical variations (Kurtzke and Hyllested, 1979), season of birth (Sadovnick et al., 2007) and migration patterns (Pugliatti et al., 2006) in the aetiology of MS. Emerging evidence supports sunlight or vitamin D as an important environmental factor in aetiology (Ramgopalan SV et al., 2009). Children exposed to parental smoking also have a higher risk of MS (Mikaeloff et al., 2007).

\subsection{Sub-types of MS}

The National MS Society in the US in 1996 categorized MS into four internationally recognized forms (Lublin and Reingold, 1996).

Relapsing-remitting: refers to MS that has exacerbations/relapses followed by symptom-free periods of remission. This is the commonest form of MS in children (Ruggierri et al., 2004).

Primary Progressive: It is characterized by gradual clinical decline from the time of disease onset with no distinct periods of remission or relapses. There maybe plateau periods during the disease but no periods of being symptom free. This entity, though rare in children, is reported (Duquette et al., 1987; Govender et al., 2010).

Secondary Progressive: This type begins with a relapsing remitting course which may last several years before the onset of the secondary progressive stage. Secondary progressive 
multiple sclerosis is a second-stage, chronic, progressive form of the disease where there are no periods of remission, only breaks in attack duration with no recovery from symptoms.

Relapsing progressive: have a steady neurologic decline but also suffer clear superimposed attacks. This is the least common of all subtypes.

An acute/ Malignant MS (Marburg variant) form presenting with a fulminant, rapidly fatal disease has also been described.

\subsection{Clinical presentation}

Children present with a wide variety of clinical symptomatology including motor, sensory, visual, cerebellar and brainstem dysfunction (Shaw and Alvord., 1987; Sindern et al., 1992; Ghezzi et al., 1997; Dale et al., 2000; Boiko et al., 2002; Pohl et al., 2006; Govender et al., 2010). Motor manifestations are described as the most common clinical presentation (Duquette et al., 1987; Sindern et al., 1992; Pohl et al., 2006). Polysymptomatic presentation is reported to be more frequent in childhood onset MS compared to adults (Ghezzi et al., 1997; Dale et al., 2000; Boiko et al., 2002). However monosymptomatic presentation is also reported in children (Duquette et al., 1987). Encephalopathy and seizures also occur in MS (Gusev et al., 2002). Eye involvement is described in up to $50 \%$ of children with MS (Pohl et al., 2006). Optic neuritis in MS is more likely to be unilateral (Dale et al., 2000). Optic tract involvement may be asymptomatic and diagnosed only by abnormal visual evoked potentials (Pohl et al., 2006). Fatigue in children is more frequent compared to adults with MS (Gusev et al., 2002). Cognitive decline is reported in 30$66 \%$ of children with MS (Banwell and Anderson 2005; Banwell et al., 2007a).

\subsection{Laboratory evaluation}

Diagnostic evaluation is to exclude other conditions affecting predominantly the white matter and to look for supportive evidence for MS. The workup should also include CSF studies (including cell count, total protein, IgG index, evidence of oligoclonal bands, and cytology) (Hahn et al., 2007). CSF Oligoclonal bands are reported in $72-84 \%$ of children with MS (Sindern et al., 1992; Dale et al., 2000). Oligoclonal bands may be absent initially and only develop during the course of the illness. Leucocytosis in the peripheral blood, though described in MS (Dale et al., 2000; Govender et al., 2010), is uncommon and non-specific. Neuro-physiological testing such as visual and auditory evoked potentials are also of diagnostic importance in detecting sub-clinical evidence of demyelination.

\subsection{Imaging}

Lesions of MS are typically multiple, discrete, plaque-like and involve predominantly the white matter (Mikaeloff et al., 2004). Commonly involved areas in MS include the corpus callosum, periventricular and sub-cortical white matter (Fig 9a-g). Lesions of MS are typically iso- or hypo-intense on T1WI, and hyper-intense on T2W1 and FLAIR sequences. Enhancement of active lesions post-gadolinium may be solid, ring-like or arc-like (Fig 10a-c). Children tend to have fewer lesions and less enhancement (Banwell et al., 2007b). However, some children lack typical MRI findings of MS and have either large tumefactive lesions with peri-lesional oedema (Hahn et al., 2004) or deep grey matter involvement. Basal ganglia affectation in MS, though described, is uncommon (Figure $11 \mathbf{a}, \mathbf{b})$. Younger children with MS may also have more diffuse, bilateral ill defined lesions (Mikaeloff et al., 2004). The International Pediatric MS Study Group strongly recommended additional imaging of the entire spinal cord to identify other sites of demyelination (Figure $12 \mathbf{a}, \mathbf{b}$ ). The cervical spinal cord is the commonest region involved in MS. 


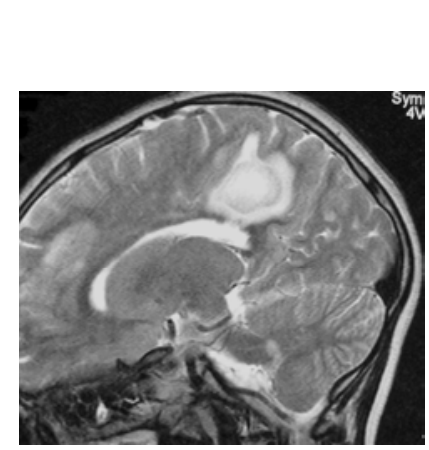

A
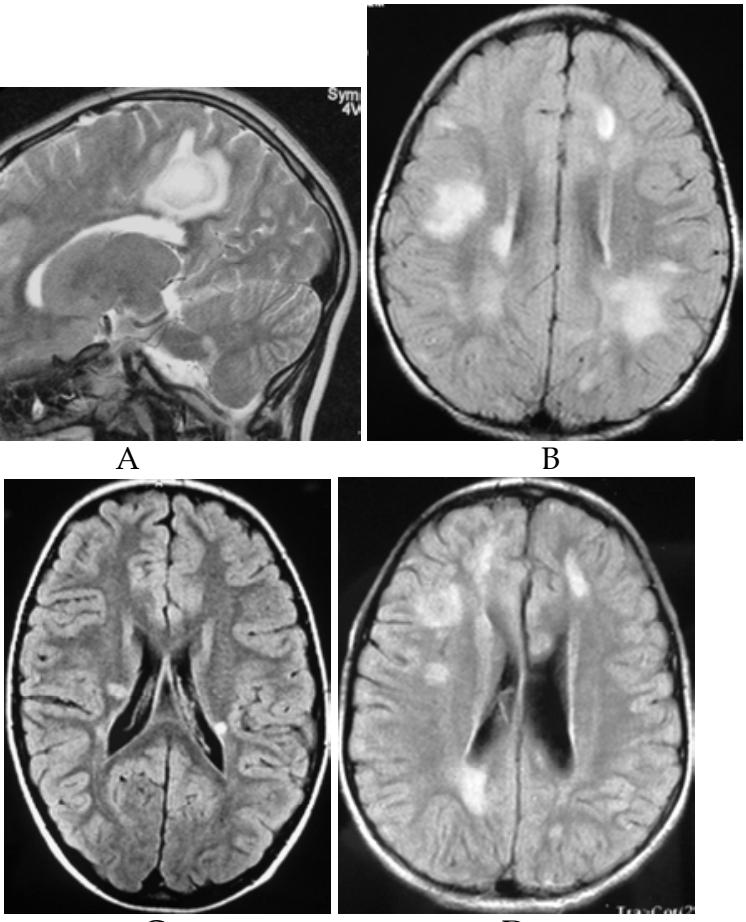

B

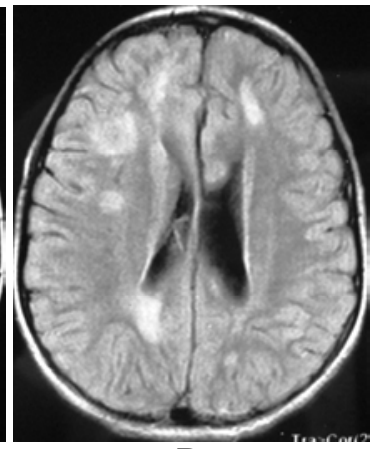

C

$\mathrm{D}$

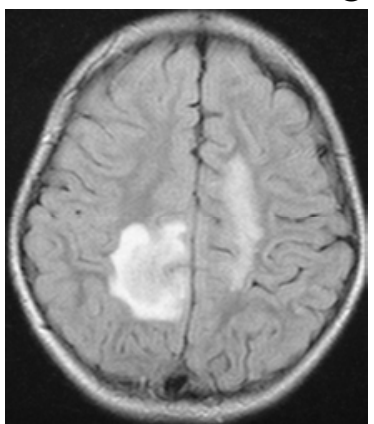

$\mathrm{E}$

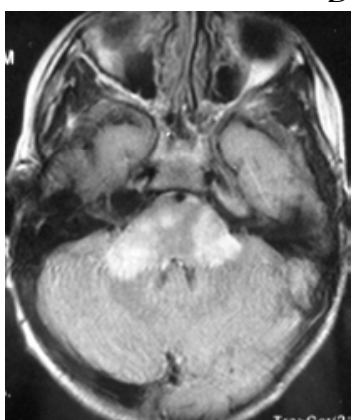

$\mathrm{F}$

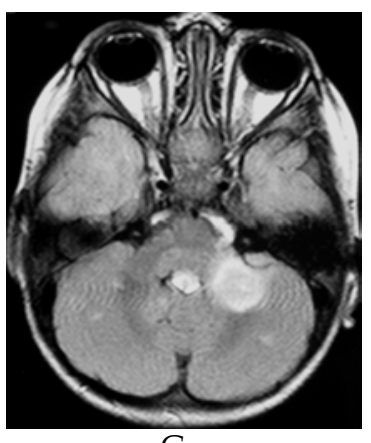

G

Fig. 9. A- T2 parasagittal MRI of the brain demonstrating flame-shaped hyper-intense lesion perpendicular to lateral ventricle consistent with MS. B- Flair axial MRI demonstrating multiple asymmetrical hyper-intense plaque-like lesions in the centrum-semiovale. Features are consistent with MS. C-Flair axial MRI of brain demonstrating 2 periventricular hyperintense white matter lesions consistent with MS. D- Flair axial at level of lateral ventricles demonstrating asymmetrical hyper-intense white matter lesions consistent with demyelination and MS. E- Flair axial of brain demonstrating hyper-intense right parietal white matter plaque-like lesion and left subtle white matter hyperintensity consistent with MS. F- Flair axial of brainstem demonstrating pontine and brachium pontis high signal intensity lesions consistent with demyelination. G-Flair axial MRI demonstrating rounded hyper-intense lesion in left brachium pontis consistent with demyelination. 


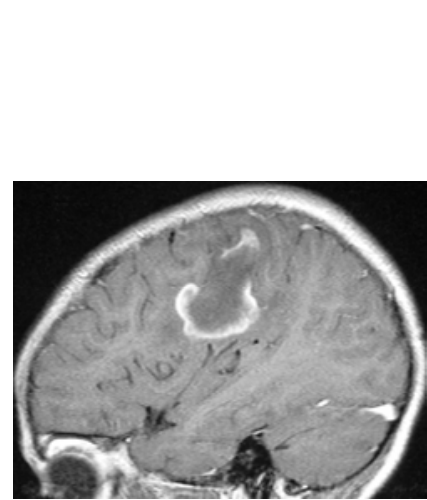

A

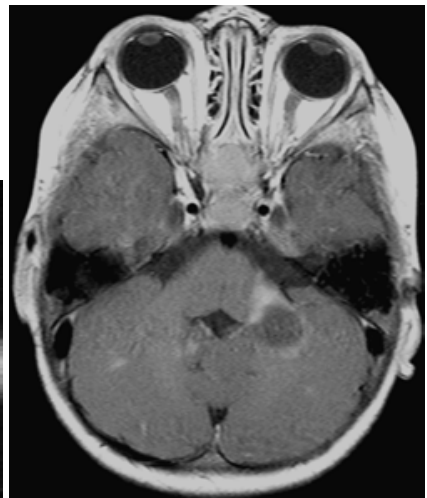

B

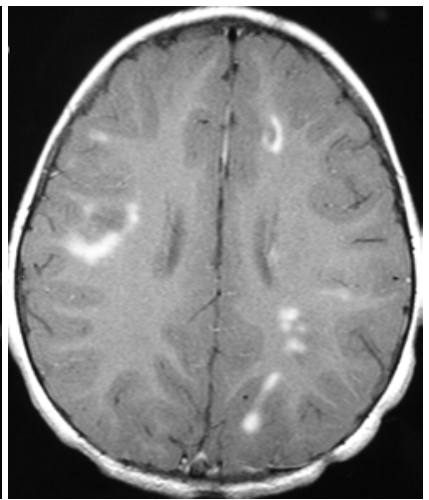

C

Fig. 10. A- T1 with contrast parasagittal MRI of brain demonstrating rim-enhancing plaquelike lesion typical of active demyelination in a patient with MS. B- T1 with contrast axial MRI demonstrating ring enhancement of left brachium pontis lesion consistent with active demyelination in a patient with MS. C- T1 with contrast axial MRI demonstrating ill-defined irregular marginal enhancement of the plaque-like lesions consistent with active demyelination in a patient with MS.

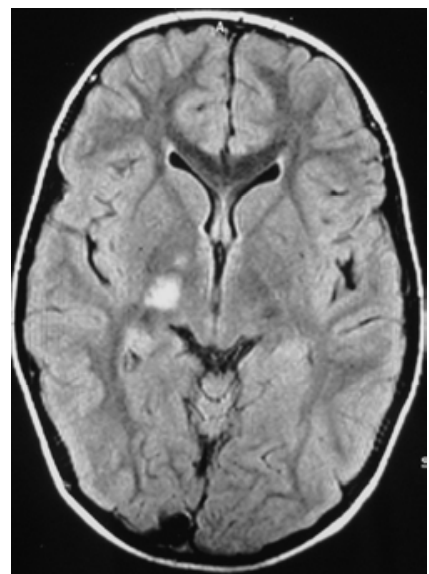

A

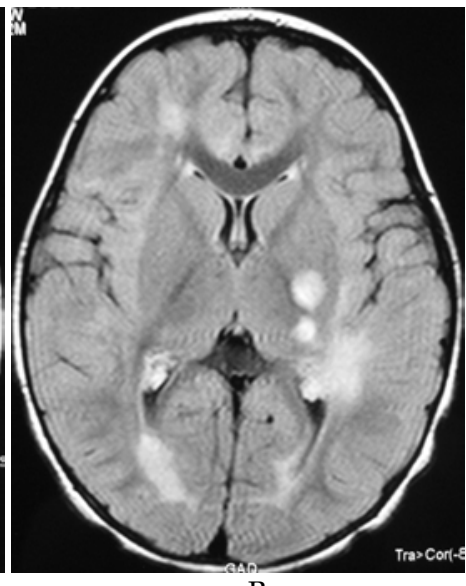

B

Fig. 11. A- Flair axial MRI of brain demonstrating 2 lesions in the right basal ganglia. This is unusual for MS. B- Flair axial MRI demonstrating multiple hyper-intense lesions in the periventricular white matter as well as left basal ganglia(atypical) consistent with MS.

MRS reveals a reduction in NAA and an elevation in choline, lipids and lactate in active lesions (Smith AB, 2009). Volumetric MRI studies reveal progressive loss of tissue in white matter tracts early in the course of the disease (Miller et al., 2002). A single study of Magnetization transfer imaging and Diffusion tensor imaging in children with MS suggested that there was no evidence of white matter degeneration in normal appearing white matter areas (Tintore et al., 2000). 


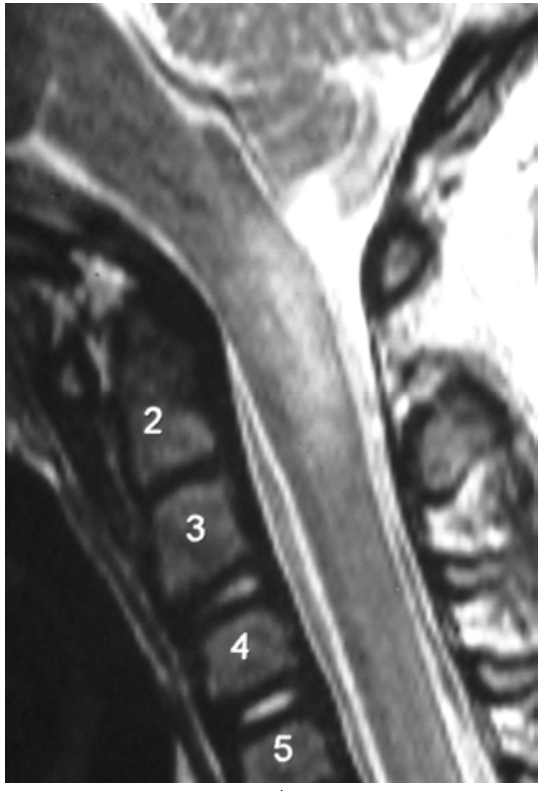

A

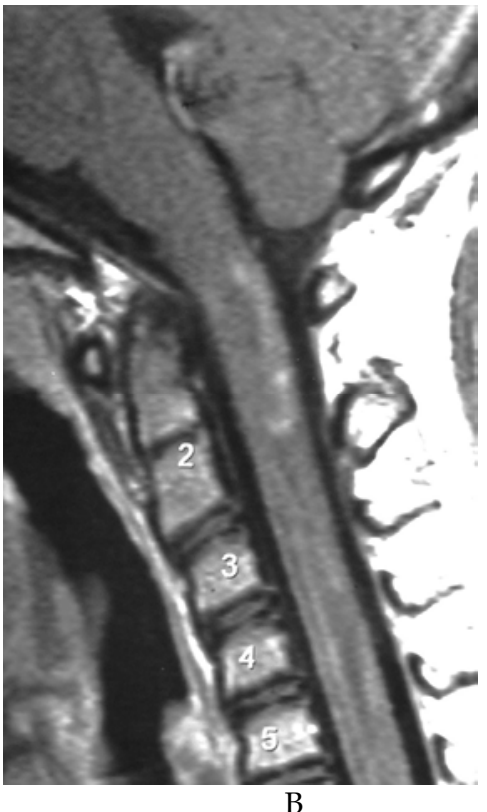

B

Fig. 12. A- T2 sagittal MRI of cervical spine in a patient with MS demonstrating an ill-defined expansile hyper-intense lesion in the proximal cord consistent with demyelination. B- T1 with contrast sagittal MRI of cervical spine in a patient with MS demonstrating ill-defined contrast enhancement of the lesion in 12A consistent with active demyelination.

\subsection{Treatment}

MS is a chronic condition with significant impact on all aspects of the family's life. Management should be trans-disciplinary involving psychologists, physiotherapists, occupational therapists and school teachers.

\subsubsection{Management of relapses}

The mainstay of managing relapses is high dose corticosteroids. High dose IV corticosteroids $(10-30 \mathrm{mg} / \mathrm{kg} /$ day) for 3-5 days, is usually used with an optional oral tapering dose. High dose oral steroids were found to be efficacious in adults (Morrow et al., 2004). Plasmapharesis and IVIG are alternatives to be considered if steroids are not effective (Hahn et al., 1996; Duzova and Bakkaloglu, 2008).

\subsubsection{Disease modifying therapy}

These therapies are known to alter the disease course and outcomes. They reduce the frequency and severity of relapses (Mikaeloff et al., 2001; Kornek et al., 2003; Tenembaum and Segura, 2006;). Patients on therapy are shown to have better outcomes compared to untreated patients (Mikaeloff et al., 2008). First line agents include Interferon beta 1a, 1b and Glatimer acetate. Case reports of second line therapies used include Natalizumab, Cyclophosphamide and Mitoxantrone. 


\begin{tabular}{|l|l|l|l|}
\hline Study & No. of patients & Treatment & Outcomes \\
\hline Ghezzi et al, 2007 & 52 & Interferon beta 1a & $\begin{array}{l}\text { Reduction in } \\
\text { relapse rate } \\
\text { Reduction in *EDSS } \\
\text { score }\end{array}$ \\
\hline $\begin{array}{l}\text { Tenembaum and } \\
\text { Segura, 2006 }\end{array}$ & 24 & Interferon beta 1a & $\begin{array}{l}\text { Reduction in } \\
\text { relapse rate }\end{array}$ \\
\hline Kornek et al 2003 & 7 & Glatimer Acetate & $\begin{array}{l}\text { Reduction in } \\
\text { relapse-2/7 } \\
\text { Stable EDSS- 3/7 }\end{array}$ \\
\hline Huppke et al, 2008 & 3 & Natalizumab & $\begin{array}{l}\text { Induction of } \\
\text { remission in all }\end{array}$ \\
\hline Makhani et al, 2009 & 17 & Cyclophosphamide & $\begin{array}{l}\text { Reduction in } \\
\text { relapse rate } \\
\text { Stabilization of } \\
\text { EDSS }\end{array}$ \\
\hline
\end{tabular}

* EDSS: Extended Disability Status Scale

Table 2. Studies of specific treatment interventions in MS

\subsection{Prognosis}

Most children with MS follow a relapsing, remitting course with increasing neurodisability (Boiko et al., 2002). A slower rate of progression of disease compared to adults suggests more plasticity and potential for recovery in the developing CNS (Simone et al., 2002). Children tend to have more relapses in the first 2 years of the disease (Simone et al., 2002; Mikaeloff et al., 2006). Patients with childhood-onset MS also take longer to reach the stage of severe disability but reach irreversible neurological disability at a younger age compared to patients with adult onset disease (Renoux et al., 2007). More severe disease was noted in girls; when the time between the first and second attacks was <1 year; for childhood-onset multiple sclerosis fulfilling MRI diagnostic criteria at onset; for an absence of severe mental state changes at onset; and for a progressive course (Mikaeloff $e t$ al., 2006).

\section{Clinically isolated syndromes}

These episodes may be mono-focal (the clinical features can be attributed to a single CNS site) or multi-focal if the clinical features can not be explained by a single lesion. These include isolated optic neuritis, transverse myelitis, brainstem (Fig 13 a-d) or cortical lesions. Typically in contrast to ADEM there is no associated fever or encephalopathy. A CIS often poses a diagnostic and therapeutic challenge. Multiple lesions ( $>4$ lesions) (Morissey et al., 1993) on the MRI increase the risk of evolution to MS. In adult studies up to $80 \%$ of patients with a CIS evolve MS (Brex et al., 2002). Brainstem lesions in CIS are associated with a worse prognosis (Tintore et al., 2010). Children with CIS tend to have more infra-tentorial lesions 


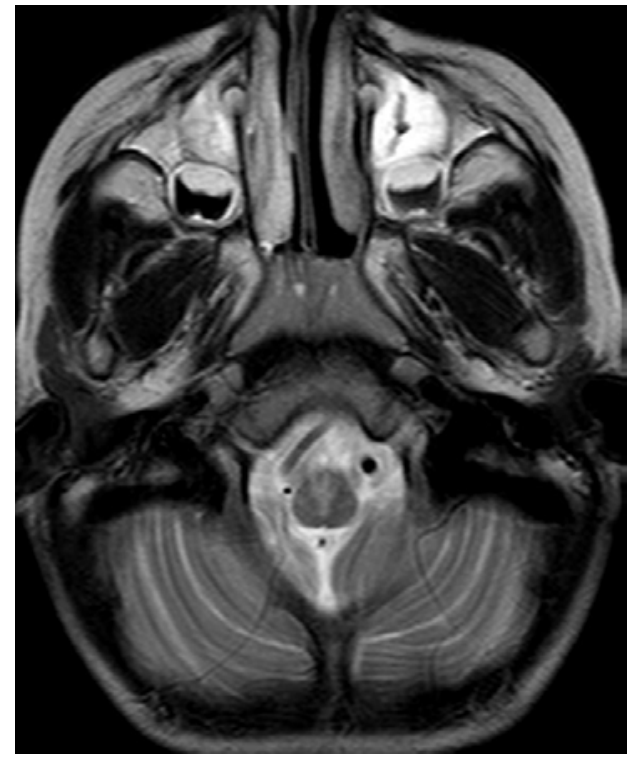

A

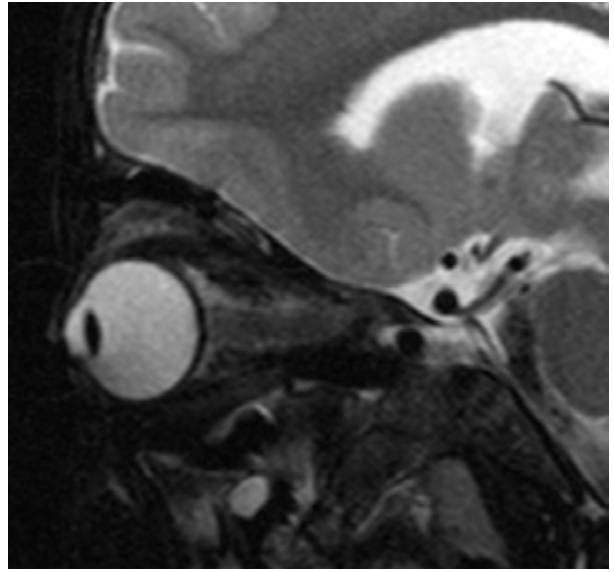

C

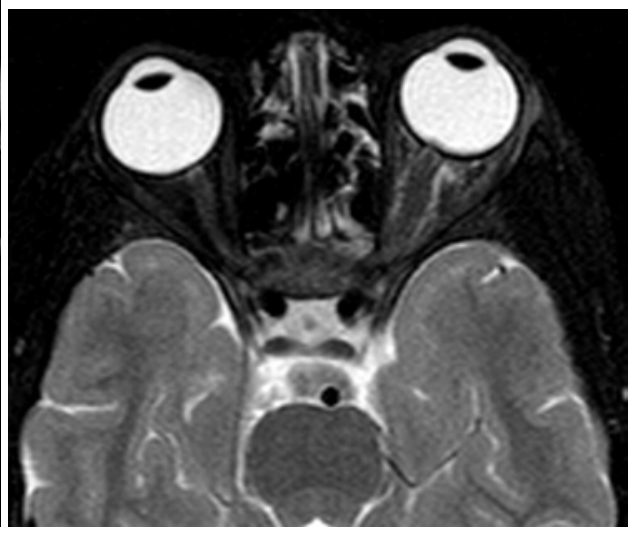

B

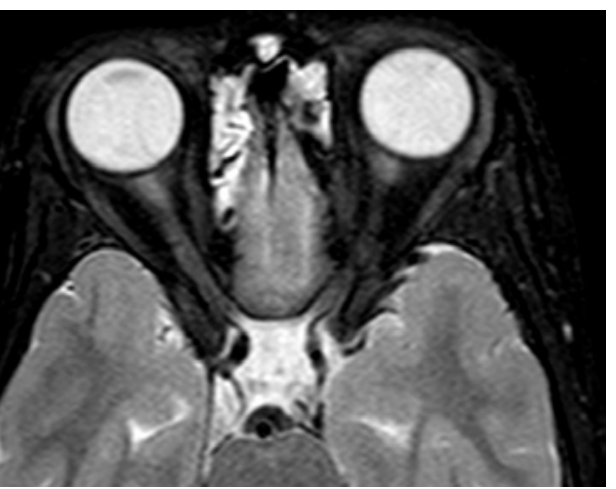

$\mathrm{D}$

Fig. 13. (B\&C same patient) Clinically Isolated Syndrome. A- T2 axial MRI demonstrating abnormal increased signal in the brainstem which was the only abnormal lesion. Clinically this patient had a CIS. B- T2 fat saturation axial MRI demonstrating a left swollen hyperintense optic nerve with resultant proptosis. Features consistent with a unilateral Optic Neuritis. Remainder of brain and spine were normal. C- T2 fat saturation sagittal oblique MRI demonstrating a left swollen hyper-intense optic nerve. Features consistent with a unilateral Optic Neuritis. Remainder of brain and spine were normal. D- T2 fat saturation axial MRI of the optic nerves demonstrating abnormal high signal intensity within the proximal portions of the nerves and swelling of the nerves. Features consistent with Optic Neuritis (worse on the right). Remainder of brain and spine were normal. 


\begin{tabular}{|c|c|c|c|}
\hline Characteristic & & ADEM & $1^{\text {st }}$ MS event \\
\hline \multirow[t]{5}{*}{ Demographics } & Age of presentation & Younger & Onset $>10 y r s$ \\
\hline & Sex & $\begin{array}{l}\text { Slight male } \\
\text { predominance }\end{array}$ & $\begin{array}{l}\text { Female } \\
\text { predominance }\end{array}$ \\
\hline & $\begin{array}{l}\text { History of Pre- } \\
\text { demyelinating event }\end{array}$ & More frequent & Less frequent \\
\hline & Seasonal distribution & More frequent & Less frequent \\
\hline & $\begin{array}{l}\text { Family history of } \\
\text { demyelinating disease }\end{array}$ & Not present & More frequent \\
\hline \multirow{5}{*}{$\begin{array}{l}\text { Clinical } \\
\text { Presentation }\end{array}$} & Seizures & More frequent & Less frequent \\
\hline & Encephalopathy & More frequent & Less frequent \\
\hline & Headache, fever & More frequent & Less frequent \\
\hline & Optic Neuritis & Bilateral & $\begin{array}{l}\text { More frequent } \\
\text { Unilateral }\end{array}$ \\
\hline & $\begin{array}{l}\text { Mono-focal vs. Poly- } \\
\text { focal signs }\end{array}$ & Polysymptomatic & Mono-focal \\
\hline \multirow{4}{*}{$\begin{array}{l}\text { Laboratory } \\
\text { features }\end{array}$} & Elevated CSF protein & Less frequent & More frequent \\
\hline & Leucocytosis in CSF & More frequent & Less frequent \\
\hline & $\begin{array}{l}\text { Oligoclonal bands in } \\
\text { CSF }\end{array}$ & $\begin{array}{l}\text { Less/ Usually } \\
\text { transient }\end{array}$ & $\begin{array}{l}\text { More frequent } \\
\text { Persistent }\end{array}$ \\
\hline & Serum Leucocytosis & More frequent & Less frequent \\
\hline \multirow{10}{*}{$\begin{array}{l}\text { MRI } \\
\text { Characteristics }\end{array}$} & Lesion definition & Ill Defined & Well-defined \\
\hline & Lesion load & Greater & Lower \\
\hline & Periventricular Lesions & Less frequent & More frequent \\
\hline & Juxta-cortical Lesions & More frequent & Less frequent \\
\hline & Cortical Lesions & More frequent & Less frequent \\
\hline & $\begin{array}{l}\text { Corpus Callosum } \\
\text { Involvement }\end{array}$ & Less frequent & More frequent \\
\hline & Brainstem/ Cerebellum & More frequent & Less frequent \\
\hline & $\begin{array}{l}\text { Spinal Cord } \\
\text { Involvement }\end{array}$ & More frequent & Less frequent \\
\hline & $\begin{array}{l}\text { Deep Grey matter } \\
\text { involvement }\end{array}$ & More frequent & Less frequent \\
\hline & Contrast enhancement & Less frequent & More frequent \\
\hline \multirow[t]{2}{*}{ Outcome } & Cognitive deficits & Less frequent & More frequent \\
\hline & $\begin{array}{l}\text { No neuro deficit after } 1^{\text {st }} \\
\text { event }\end{array}$ & Less likely & More likely \\
\hline
\end{tabular}

Table 3. Markers comparing ADEM to a first episode of MS 


\begin{tabular}{|c|c|c|c|}
\hline Disorder & Example & Clinical/ Laboratory & Radiological \\
\hline \multirow[t]{2}{*}{ Infections } & $\begin{array}{l}\text { HIV } \\
\text { Encephalopathy }\end{array}$ & $\begin{array}{l}\text { Developmental delay, } \\
\text { pyramidal tract signs, } \\
\text { microcephaly }\end{array}$ & $\begin{array}{l}\text {-Confluent bilateral } \\
\text { symmetrical white } \\
\text { matter changes } \\
\text {-cerebral atrophy } \\
\text {-basal ganglia } \\
\text { calcification }\end{array}$ \\
\hline & $\begin{array}{l}\text { Progressive Multi- } \\
\text { focal } \\
\text { Leucoencephalopa } \\
\text { thy (JC Virus) }\end{array}$ & Immunocompromised & $\begin{array}{l}\text {-Multi-focal } \uparrow \mathrm{T} 2 \mathrm{WI} \\
\text { lesions } \\
\text {-Propensity for } \\
\text { frontal/ parieto- } \\
\text { occipital areas } \\
\text {-Subcortical U } \\
\text { fibres involved }\end{array}$ \\
\hline Other infections & \multicolumn{3}{|c|}{$\begin{array}{l}\text { Sub-acute Sclerosing Panencephalitis, Lymes Disease, } \\
\text { Neurosyphillus, HTLV1, Borreliosis }\end{array}$} \\
\hline \multirow[t]{2}{*}{$\begin{array}{l}\text { Auto- } \\
\text { immune/Vasculitides }\end{array}$} & $\begin{array}{l}\text { Systemic Lupus } \\
\text { Erythematosus }\end{array}$ & $\begin{array}{l}\text { Multi-system auto- } \\
\text { immune disorder } \\
\text { Anti-nuclear factor } \\
\text { positive }\end{array}$ & $\begin{array}{l}\text {-Multi-focal } \\
\uparrow T 2 W I / F L A I R \\
\text {-Infarcts } \\
\text {-Contrast } \\
\text { enhancement } \\
\text { of active } \\
\text { lesions }\end{array}$ \\
\hline & \multicolumn{3}{|c|}{ Isolated CNS angiitis, CADASIL (adult disorder-rare in children) } \\
\hline \multirow[t]{2}{*}{ Tumor } & CNS Lymphoma & $\begin{array}{l}\text { Insiduous onset, CSF } \\
\text { cytospin -malignant cells }\end{array}$ & $\begin{array}{l}-\downarrow \text { T1WI } \\
-\uparrow \text { T2WI } \\
- \text { GM involved more } \\
\text { frequently } \\
- \text { MRS may help }\end{array}$ \\
\hline & \multicolumn{3}{|c|}{ Medulloblastoma, Astrocytoma } \\
\hline Leukodystrophies & $\begin{array}{l}\text { Adrenoleukody- } \\
\text { strophy }\end{array}$ & $\begin{array}{l}\text { Boys with } \\
\text { hyperpigmentation of } \\
\text { skin, behaviour and } \\
\text { learning problems, } \\
\text { Abnormal very long chain } \\
\text { fatty acids }\end{array}$ & $\begin{array}{l}\text {-Symmetrical, } \\
\text { confluent } \\
\text {-predominantly } \\
\text { posterior } \\
\text { involvement } \\
\text {-Splenium and } \\
\text { cortico-spinal tracts } \\
\text { involved } \\
\text {-Leading edge } \\
\text { enhancement in } \\
\text { peri-trigonal } \\
\text { area }\end{array}$ \\
\hline
\end{tabular}




\begin{tabular}{|c|c|c|c|}
\hline \multirow[b]{2}{*}{ Mitochondrial } & \multicolumn{3}{|c|}{$\begin{array}{l}\text { Metachromic Leukodystrophy, Krabbe's Disease, Alexander's } \\
\text { disease }\end{array}$} \\
\hline & Leigh's Disease & $\begin{array}{l}\text { Neuro-regression with } \\
\text { dystonia/opthalmoplegia } \\
\text { Hyperlactataemia }\end{array}$ & $\begin{array}{l}\text {-Bilateral } \\
\text { symmetrical } \\
\uparrow T 2 W I / F L A I R \text { of } \\
\text { Putamen and } \\
\text { caudate nuclei } \\
\text {-Can have diffuse } \\
\text { cortical WM } \\
\text { hyperintensities }\end{array}$ \\
\hline \multirow[t]{2}{*}{$\begin{array}{l}\text { Nutritional } \\
\text { Deficiencies }\end{array}$} & $\begin{array}{l}\text { Vitamin B12 } \\
\text { deficiency }\end{array}$ & $\begin{array}{l}\text { Anaemia, peripheral } \\
\text { neuropathy, Myelopathy }\end{array}$ & $\begin{array}{l}\text {-Periventricular } \\
\uparrow \mathrm{T} 2 \mathrm{WI}\end{array}$ \\
\hline & \multicolumn{3}{|c|}{ Vitamin E, Folate deficiency } \\
\hline \multirow[t]{2}{*}{ Toxins/ Drugs } & Radiation & History of exposure & $\begin{array}{l}\text {-Diffuse, bilateral } \\
\text { periventricular and } \\
\text { central WM } \\
\text { involved } \\
\text {-T1WI } \downarrow, \text { T2WI } \uparrow \\
\text {-Sparing of sub- } \\
\text { cortical U Fibres }\end{array}$ \\
\hline & \multicolumn{3}{|l|}{ Lead, Isoniazid } \\
\hline \multirow[t]{2}{*}{ Infiltrative } & Sarcoidosis & $\begin{array}{l}\text { Cranial neuropathies, } \\
\text { aseptic meningitis, visual } \\
\text { disturbances }\end{array}$ & $\begin{array}{l}\text {-Discrete } \\
\text { periventricular } \\
\text { lesions } \\
\text {-May have } \\
\text { hypothalamic and } \\
\text { meningeal } \\
\text { enhancement }\end{array}$ \\
\hline & Histiocytosis & $\begin{array}{l}\text { Visual disturbances, } \\
\text { hypothalamic dysfunction }\end{array}$ & $\begin{array}{l}\text {-Hypothalamic/ } \\
\text { cerebellar T1WI } \downarrow \text {, } \\
\text { T2WI } \uparrow \\
\text {-Skull/ mastoid } \\
\text { lesions }\end{array}$ \\
\hline $\begin{array}{l}\text { Osmotic } \\
\text { Demyelination } \\
\text { Syndrome }\end{array}$ & & $\begin{array}{l}\text { Rapid correction of Hypo- } \\
\text { or hypernatraemia }\end{array}$ & $\begin{array}{l}\text {-Symmetric } \\
\text { changes in BG/ } \\
\text { Cerebral cortical } \\
\text { WM } \\
\text {-T1WI } \downarrow \\
-\uparrow \text { FLAIR/T2WI } \uparrow \\
\text {-Pontine : Usual } \\
\text { central with } \\
\text { sparing of cortico- } \\
\text { spinal tracts }\end{array}$ \\
\hline
\end{tabular}

Table 4. Main differential diagnosis of acquired white matter diseases on MRI 
(Ghassemi et al., 2008). This may be related to the differences in myelination patterns and maturation in children compared to adults. A radiologically isolated syndrome (RIS) is defined by incidental MRI findings suggestive of MS in an asymptomatic patient lacking any history, symptoms, or signs of MS (Okuda et al., 2009).

\section{Risk of recurrence after a first demyelinating event}

Predicting the risk of a first episode of demyelination evolving on to MS is important as new immunomodulating therapies become available. Early initiation of disease modifying therapy reduces the risk of relapse and long-term disability (Jacobs et al., 2000). Patients with "ADEM" progressing to MS vary from 0-29\% (Belman et al., 2007). Multiple historical, clinical, laboratory and radiological criteria are used to predict the risk of recurrence/ progression to MS (Table 3).

A seasonal pattern, a history of a precipitant, seizures, bilateral optic neuritis and encephalopathy are considered more likely in ADEM compared to MS (Dale et al., 2005). Inflammatory markers, a high cerebrospinal fluid protein and leucocytosis are also more common in ADEM (Kesselring et al., 1990). MRI characteristics that are predictive of evolution to MS include well defined lesions that are peri-aqueductal or perpendicular to the corpus callosum (Dale et al., 2000), deep grey matter involvement and lesions that enhance post contrast (Govender et al., 2010).

\section{Differential diagnosis of white matter disease in children}

The differential diagnosis for a child who presents with a neurological symptom and white matter lesions on neuro-imaging is vast and includes infectious diseases, leukodystrophies, tumors, vasculitides, toxins and vitamin deficiencies. In resource poor countries, CNS infections must be excluded first as they are common and have acute therapeutic implications.

CNS infections must be excluded in children presenting acutely especially with fever and encephalopathy. CNS infections that may present with multifocal white matter lesions include HTLV-1, Borreliosis and Subacute Sclerosing Panencephalitis. In resource poor settings HIV Encephalopathy (Figure $\mathbf{1 4} \mathbf{a}, \mathbf{b}$ ) is common and is also characterized by confluent white matter lesions. Progressive Multi-focal Leukoencephalopathy (Figure 14 c), is also common in immuno-compromised patients.

Neurometabolic disorders, such as Adrenoleukodystrophy (Figure $14 \mathbf{d}, \mathbf{e}$ ), presents with primary white matter disease.

Osmotic Myelinolysis (Figure $14 \mathbf{f}, \mathbf{g}$ ) is thought to be related to osmotic shifts associated with rapid correction of fluid and electrolyte abnormalities (especially sodium abnormalities). Malnourished children are at greater risk for developing myelinolysis. Lesions typically occur in the pons but have also been reported in extra-pontine sites such as the basal ganglia, cerebral cortex and cerebellar peduncles.

Nutritional deficiencies such as vitamins B12, E and folate deficiencies may also cause white matter lesions.

Drugs and toxins implicated in demyelination include tin, lead, isoniazid and radiation.

Collagen Vascular Diseases refer to a group of auto-immune mediated disorders. The neurological manifestations are diverse. Neuro-imaging may show multi-focal white matter lesions- involving the cortex, cerebellum or spinal cord. 


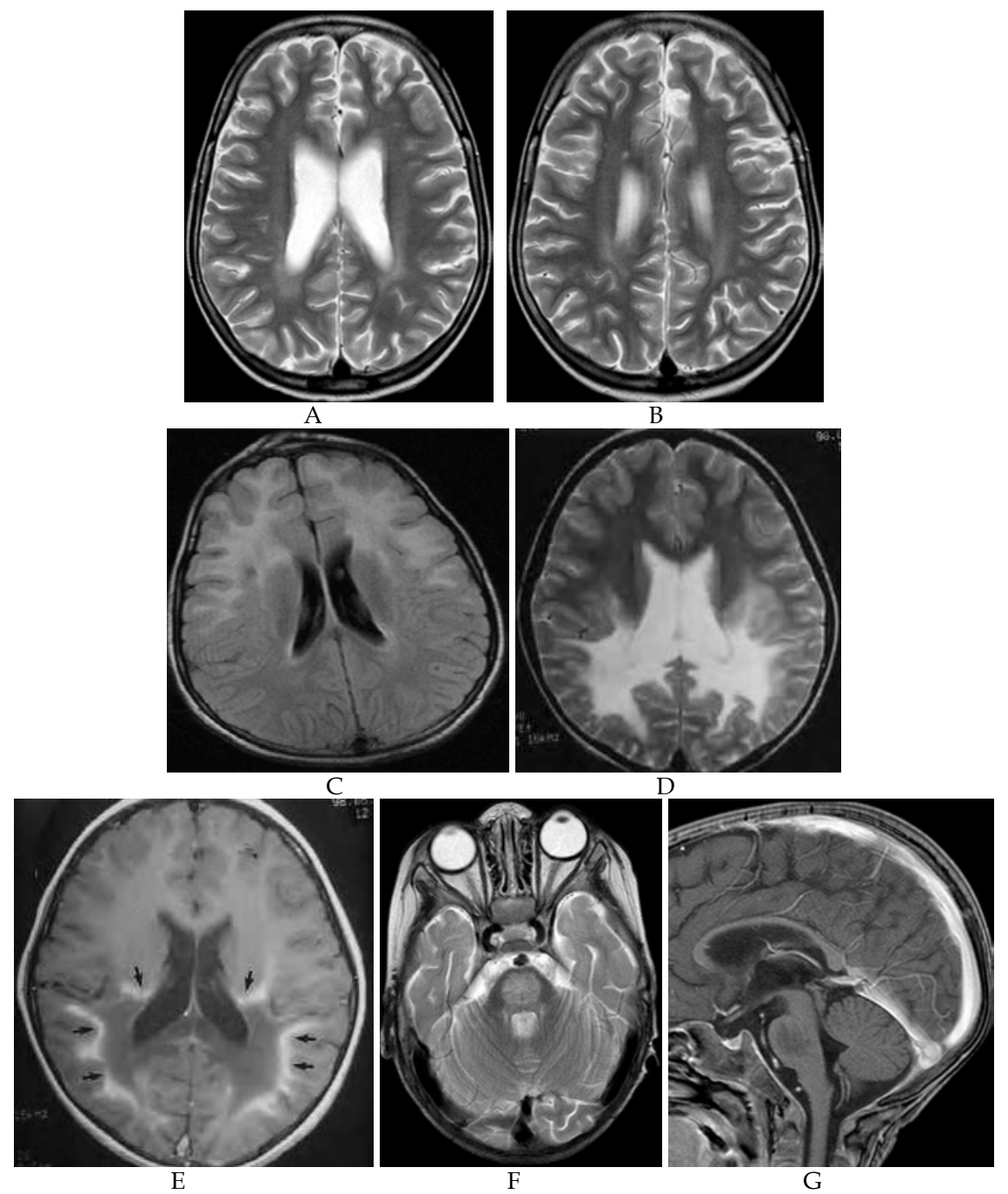

Fig. 14. A \& B- T2 axial MRI demonstrating diffuse brain shrinkage/atrophy with ex-vacuo dilatation of the ventricles and abnormal increased signal intensity in the deep white matter bilaterally. This patient has features of HIV encephalopathy. C- Flair axial MRI

demonstrating bilateral symmetrical increased signal intensity in the frontal white matter. This patient was diagnosed with PML. D- T2 axial MRI demonstrating bilateral symmetrical confluent abnormal increased white matter signal intensity in the posterior white matter consistent with Adrenoleukodystrophy. E- T1 with contrast axial MRI of same patient as 14D demonstrating peripheral enhancement of the white matter lesions. F- T2 axial MRI demonstrating well-defined rounded hyper-intense lesion in the pons. Note peripheral sparing of the pons. (Compared to figure 14G). Features consistent with Osmotic/ Pontine Myelinolysis. G- T1 with contrast sagittal MRI of the same pontine lesion as 14F showing no contrast enhancement. Features consistent with Pontine Myelinolysis. 


\section{Conclusion}

Acquired demyelinating disorders in children are a diverse, challenging group of conditions that are probably under-diagnosed. Early recognition is essential for optimal patient management as some of these disorders cause significant long-term sequelae. Advances in the last decade include establishing consensus definitions and improvement in neuroimaging techniques. These advances set the stage for international collaborative studies to better define other areas such as understanding the aetio-pathogenesis, identifying biomarkers and standardizing treatment protocols of this diverse group of conditions.

\section{References}

Abramsky O, Teitelbaum D, Arnon R (1977). Effect of a synthetic polypeptide (cop1) on patients with multiple sclerosis and with acute disseminated encephalomyelitis. $J$ Neurol Sci 31: 433-8.

Adams C, Armstrong D (1990). Acute transverse myelopathy in children. Can J Neurol Sci 17: 40-5.

Afifi AK, Bell WE, Menezes AH, Moore SA (1994). Myelinoclastic diffuse sclerosis (Schilder's disease): report of a case and review of the literature. J. Child Neurol. 9 (4): 398-403

Alvord EC Jr, Jahnke U, Fischer EH, Kies MW, Driscoll BF, Compston DA (1987). The multiple Causes of Multiple sclerosis: the importance of age of infections in childhood. J Child Neurol. 2: 313-21

Andronikou S, Albuquerque-Jonathan G, Wilmshurst J, Hewlett R (2003). MRI findings in acute idiopathic transverse myelopathy in children. Pediatr Radiol 33:624-629

Arnold DL, Matthews PM, Francis G, Antel J (1990). Proton magnetic resonance spectroscopy of human brain in vivo in the evaluation of multiple sclerosis: assessment of the load of disease. Magnet Reson Med 14: 154 -159.

Aulchenko YS, Hoppenbrouwers IA, Ramagopalan SV, Broer L, Jafari N, Hillert J, Link J, Lundström W, Greiner E, Dessa Sadovnick A, Goossens D, Van Broeckhoven C, Del-Favero J, Ebers GC, Oostra BA, van Duijn CM, Hintzen RQ (2008). Genetic variation in the KIF1B locus influences susceptibility to multiple sclerosis. Nat Genetics 40(12): 1402-3

Banwell B, Kennedy J, Sadovnick D, Magalhaes S et al (2009). Incidence of acquired demyelination of the CNS in Canadian children. Neurology 72(3): 232-239

Banwell B, Ghezzi A, Bar-Or A, Mikaeloff Y, Tardieu M (2007a). Multiple sclerosis in children: Clinical diagnosis, therapeutic strategies, and future directions. Lancet Neurol. 6: 887-902.

Banwell BL, Anderson PE (2005). The cognitive burden of multiple sclerosis in children. Neurology 64: 891-4.

Banwell B, Shroff M, Ness JM, Jeffery D, Schwid S, Weinstock-Guttman, B; for the International Pediatric MS Study Group (2007b). MRI features of pediatric multiple sclerosis. Neurology 68(16) Suppl 2, pp S46-S53

Barkovich JA, Moore KR, Grant E, Jones BV, Vezina G, Koch BL, Raybaud C, Blaser S, Hedlund GB, Illner A (2007). Diagnostic Imaging: Pediatric Neuroradiology (1st edition), Amirsys-Elsevier, ISBN 1-4160-4918-5 Salt Lake City, Utah 
Baum PA, James Barkovich A, Koch TK (1994). Deep gray matter involvement in children with acute disseminated encephalomyelitis. AJNR 15: 1275-1283

Belman A, Tanuja C, Renoux C, Waubant E for the International Pediatric MS Study Group (2007). Challenges in the classification of Paediatric MS and future directions. Neurology 68(16): pp S70-74

Berman M, Feldman S, Alter M, Zilber N, Kahana E (1981). Acute transverse myelitis: incidence and etiological considerations. Neurology 31: 966-971

Bhigjee AI, Moodley K, Ramkissoon K (2007). Multiple sclerosis in KwaZulu Natal, South Africa: an Epidemiological and clinical study. Multiple Sclerosis 13(9): 1095-1099

Boe J, Solberg CO, Saeter T. Corticosteroid treatment of acute meningo encephalitis: Retrospective study of 346 cases (1965). BMJ 1: 1094-5

Boiko A, Vorobeychik G, Paty D, Devonshire V, Sadovnick V (2002). Early onset multiple sclerosis: A Longitudinal study. Neurology 59: 1006-1010

Bortone E, Bettoni L, Buzio S, Delsoldato S, Giorgi C, Mancia D (1996). Spindle coma and alternating pattern in the course of measles encephalitis. Clin Electroencephalogr 27: 210-4.

Boster AL, Endress CF, Hreha SA, Caon C, Perumal JS, Khan OA (2009). Pediatric-onset multiple sclerosis in African- American black and European-origin white patients. Pediatr Neurol 40: 31-33.

Bizzi A, Ulug AM, Crawford TO, Passe T, Bugiani M, Bryan RN, Barker PB (2001). Quantitative proton MR spectroscopic imaging in acute disseminated encephalomyelitis. Am J Neuroradiol 22: 1125-30

Brex PA, Ciccarelli O, O'Riordan JI, Sailer M, Thomson AJ, Miller DH (2002). A longitudinal study of abnormalities on MRI and disability from multiple sclerosis. $N$ Engl J Med 346: 158-164

Dale RC, Branson JA (2005). ADEM vs. MS Can initial presentation help in establishing a correct diagnosis? Archive of Disease in Childhood 90: 636-639

Dale RC, de Sousa C, Chong WK, Cox TC, Harding B, Neville BG (2000). Acute Disseminated Encephalomyelitis, Multiphasic disseminated encephalomyelitis and Multiple Sclerosis in Children. Brain 123: 2407-2422

Dale RC, Church AJ, Cardoso F, Goddard E, Cox TC, Kling Chong WK, Williams A, Klein NJ, Neville BG, Thomson EJ, Giovannoni G (2001). Post streptococcal acute disseminated encephalomyelitis with basal ganglia involvement and auto-reactive antibasal ganglia antibodies. Ann Neurol 50(5): 588-595.

Davies NW, Sharief MK, Howard RS ((2006). Infection-associated encephalopathies: their investigation, diagnosis, and treatment. J. Neurol. 253 (7): 833-45

Defresne P, Meyer L, Tardieu M, Scalais E, Nuttin C, De Bont B, Loftus G, Landrieu P, Kadhim H, Sébire G (2001). Efficacy of high dose steroid therapy in children with severe acute transverse myelitis. J Neurol Neurosurg Psychiatr 71: 272-4

De Goede CG, Holmes EM, Pike MG (2010). Acquired transverse myelopathy in children in the United Kingdom - A 2 year prospective study. European Journal of Paediatric Neurology 14: 479-487

De Stefano N, Matthews PM, Arnold DL (1995). Reversible decreases in N-acetylaspartate after acute brain injury. Magnet Reson Med 34: $721 \pm 727$ 
De Stefano N, Narayanan S, Matthews PM, Mortilla M, Dotti MD, Federico A, Arnold DL (2000). Proton MR spectroscopy to assess axonal damage in multiple sclerosis and other white matter disorders. Journal of NeuroVirology 6 (2): S121- S129

De Stefano N, Narayanan S, Matthews PM, Mortilla M, Dotti MD, Federico A, Arnold DL (2000). Proton MR spectroscopy to assess axonal damage in multiple sclerosis and other white matter disorders. Journal of NeuroVirology 6 (2): S121- S129

Dunne K, Hopkins IJ, Shield LK (1986). Acute transverse myelopathy in childhood. Dev Med Child Neurol 28: 198-204.

Duquette P, Murray TJ, Pleines J, Ebers GC, Sadovnick D, Weldon P, Warren S, Paty DW, Upton A, Hader W (1987). Multiple sclerosis in childhood: clinical profile in 125 patients. J Pediatr 111(3): 359-63.

Duzova A, Bakkaloglu A (2008). Central nervous system involvement in pediatric rheumatic diseases: current concepts in treatment. Curr Pharm Des 14: 1295-301

Engelbrecht V, Scherer A, Rassek M, Witsack HJ, Mödder U (2002). Diffusion-weighted MR Imaging in the Brain in Children: Findings in the Normal Brain and in the Brain with White Matter Diseases. Radiology 222: 410-418

Finsterer J, Grass R, Stollberger C, Mamoli B (1998). Immunoglobulins in acute, parainfectious, disseminated encephalo-myelitis. Clin Neuropharmacol 21: 258-61.

Ford B, Tampori D, Francis G (1992). Long term follow up of acute partial transverse myelopathy. Neurology 42: 250-252

Gabis LV, Panasci DJ, Andriola MR, Huang W (2004). Acute disseminated encephalomyelitis: An MRI/MRS longitudinal study. Pediatr Neurol 30: 324-329.

Ghassemi R, Antel SB, Narayanan S, Francis SJ, Bar-Or A, Sadovnick AD, Banwell B, Arnold DL; Canadian Pediatric Demyelinating Disease Study Group (2008). Lesion distribution in children with clinically isolated syndromes. Ann Neurol. 63(3): 401-5

Ghezzi A, Deplano V, Faroni J, Grasso MG, Liguori M, Marrosu G, Pozzilli C, Simone IL, Zaffaroni M (1997). Multiple sclerosis in childhood: clinical features of 149 cases. Mult Scler 3: 43-46.

Ghezzi A, Amato MP, Capobianco M, Gallo P, Marrosu MG, Martinelli V, Milanese C, Moiola L, Milani N, La Mantia L, Patti F, Pozzilli C, Trojano M, Comi G, Zaffaroni M; Immunomodulatory Treatment of Early-onset MS (ITEMS) Group (2007). Treatment of early-onset multiple sclerosis with intramuscular interferon beta-1a: long-term results. Neurol Sci. 28(3): 127-32

Govender R, Wieselthaler N, Ndondo AP, Wilmshurst JM (2010). Acquired Demyelinating Disorders of Childhood in the Western Cape, South Africa. J Child Neurol 25: 48-56

Gusev E, Boiko A, Bikova O, Maslova O, Guseva M, Boiko S, Vorobeichik G, Paty D (2002). The natural history of early onset multiple sclerosis: Comparison of data from Moscow and Vancouver. Clin Neurol Neurosurg 104: 203-7.

Gutling E, Landis T (1989). CT ring sign imitating tumour, disclosed as multiple sclerosis by MRI: A case report. J Neurol Neurosurg Psychiatry 52: 903-6.

Hafler DA, Compston A, Sawcer S, Lander ES, Daly MJ, De Jager PL, de Bakker PI, Gabriel SB, Mirel DB, Ivinson AJ, Pericak-Vance MA, Gregory SG, Rioux JD, McCauley JL, Haines JL, Barcellos LF, Cree B, Oksenberg JR, Hauser SL International Multiple Sclerosis Genetics Consortium (2007) Risk Alleles for Multiple Sclerosis Identified by a Genomewide Study. N Engl J Med 357(9): 851-62. 
Hahn CD, Miles BS, MacGregor DL, Blaser SI, Banwell BL, Hetherington CR (2003). Neurocognitive outcome after acute disseminated encephalomyelitis. Pediatr. Neurol. 29 (2): 117-23.

Hahn J S, Pohl, D, Rensel, M, Sanjai DO for the International Pediatric MS Study Group (2007). Differential diagnosis and evaluation in pediatric multiple sclerosis. Neurology 68(16) Suppl 2: pp S13-S22

Hahn CD, Shroff MM, Blaser SI, Banwell BL (2004). MRI criteria for multiple sclerosis: Evaluation in a pediatric cohort. Neurology 62: 806-808

Hahn JS, Siegler DJ, Enzmann D (1996). Intravenous gammaglobulin therapy in recurrent acute disseminated encephalomyelitis. Neurology 46: 1173-4.

Hung KL, Liao HT, Tsai ML (2000). Postinfectious encephalomyelitis: etiologic and diagnostic trends. J Child Neurol. 15(10): $666-670$

Hoppenbrouwers IA, Aulchenko YS, Ebers GC, Ramagopalan SV, Oostra BA, van Duijn CM, Hintzen RQ (2008). EVI5 is a risk gene for multiple sclerosis. Genes Immun 9(4): 334-7

Huppke P., Stark W., Zurcher C., Huppke B., Bruck W. and Gartner J. (2008). Natalizumab use in pediatric multiple sclerosis. Arch Neurol 65: 1655-1658.

Hynson JL, Kornberg AJ, Coleman LT, Shield L, Harvey AS, Kean MJ (2001). Clinical and neuroradiologic features of acute disseminated encephalomyelitis in children. Neurology 56: 1308-1312

Idrissova ZR., Boldyreva MN, Dekonenko EP, Malishev NA, Leontyeva IY, Martinenko IN (2003). Acute disseminated encephalomyelitis in children: clinical features and HLA-DR linkage. Eur J Neurol 10: 537-546.

Jacobs RK, Anderson VA, Neale JL, Shield LK, Kornberg AJ (2004). Neuropsychological outcome after acute disseminated encephalomyelitis: impact of age at illness onset. Pediatr. Neurol. 31 (3): 191-7.

Jacobs LD, Beck RW, Simon JH, Kinkel RP, Brownscheidle CM, Murray TJ, Simonian NA, Slasor PJ, Sandrock AW, and the CHAMPS Study Group (2000). Intramuscular interferon beta-1-a therapy initiated during a first demyelinating event in multiple sclerosis. N Engl J Med 343: 898-904

Jain AP, Gupta OP, Jajoo UN (1983). A study of some prognostic factors in acute transverse Myelitis. Journal Assoc Physicians India. 31(8): 497-9.

Jeffery DR, Mandler RN, Davis LE (1993). Transverse myelitis: retrospective analysis of 33 cases with differentiation of cases associated with multiple sclerosis and parainfectious agents. Arch Neurol. 50: 532-535

Johnson, R. T. (1994), The virology of demyelinating diseases. Annals of Neurology 36: S54S60

Johnson RT, Griffin DE, Gendelman HE (1985). Postinfectious encephalomyelitis. Semin Neurol 5: 180-90.

Kalra V, Sharma S, Sahu J, Sankhyan N, Chaudry R, Dhawan B, Mridula B (2009). Childhood acute transverse myelitis: clinical profile, outcome, and association with antiganglioside antibodies. J Child Neurol. 24: 466-471.

Kaplin AI, Krishnan C, Deshpande DM, Pardo CA, Kerr DA(2005). Diagnosis and management of acute myelopathies. Neurologist 11: 2-18 
Kaufman MD, Johnson SK, Moyer D, Bivens J, Norton HJ (2003). Multiple sclerosis: severity and progression rate in African Americans compared with whites. Am J Phys Med Rehabil 82: 582-90.

Kesselring J, Miller DH, Robb SA, Kendall BE, Moseley IF, Kingsley D, du Boulay EP, McDonald WI (1990). Acute disseminated encephalomyelitis. MRI findings and the distinction from multiple sclerosis. Brain 113: 291-302.

Kinoshita A, Hayashi M, Miyamoto K, Oda M, Tanabe H (1996). Inflammatory demyelinating polyradiculitis in a patient with acute disseminated encephalomyelitis (ADEM). J Neurol Neurosurg Psychiatry 60: 87-90.

Knebusch M, Strassburg HM, Reiners K (1998). ATM in Childhood: 9 cases and a review of the literature. Dev Med Child. Neurol 40: 631-639

Kornek B, Bernert G, Balassy C, Geldner J, Prayer D, Feucht M (2003). Glatiramer acetate treatment in patients with childhood and juvenile onset multiple sclerosis. Neuropediatrics 34(3): 120-6.

Krupp Lauren B, Banwell B, and Tenembaum $S$ for the International Pediatric MS Study Group (2007). Neurology. Vol 68(16): pp S7-S12

Kumar K, Toth C, Jay V (1998). Focal plaque of demyelination mimicking cerebral tumor in a pediatric patient. Pediatr Neurosurg 29: 60-3.

Kurtzke, J.F. and Hyllested, K (1979). Multiple sclerosis in the Faroe Islands: I. Clinical and epidemiological features. Ann Neurol 5(1): 6-21.

Leake JA, Albani S, Kao AS, Senac MO, Billman GF, Nespeca MP (2004). Acute disseminated encephalomyelitis in childhood: Epidemiologic clinical and laboratory features. Pediatr Infect Dis J 23: 756-64.

Lennon VA, Wingerchuk DM, Kryzer TJ, Pittock SJ, Lucchinetti CF, Fujihara K, Nakashima I, Weinshenker BGL (2004). A serum autoantibody marker of neuromyelitis optica: distinction from multiple sclerosis. Lancet 364: 2106-2112.

Lisak RP, Zweiman B (1977). In vitro cell-mediated immunity of cerebrospinal-fluid lymphocytes to myelin basic protein in primary demyelinating diseases. $N$ Engl J Med 297(16): 850-3.

Lublin FD, Reingold SC (1996). Defining the clinical course of multiple sclerosis: results of an international survey. National Multiple Sclerosis Society (USA) Advisory Committee on Clinical Trials of New Agents in Multiple Sclerosis. Neurology 46 (4): 907-11

Lucas J (1790). An account of uncommon symptoms succeeding the measles with additional remarks on the infection of measles and smallpox. London Med J. 11: 325 -331

Makhani N, Gorman MP, Branson HM, Stazzone L, Banwell BL, Chitnis T (2009). Cyclophosphamide use in pediatric multiple sclerosis. Neurology 72(24): 2064-5.

Mandler RN, Davis LE, Jeffery DR, Kornfeld M.(1993). Devic's neuromyelitis optica: a clinicopathological study of 8 patients. Ann Neurol 34(2): 162-8.

McAdam LC, Blaser SI, Banwell BL (2002). Pediatric tumefactive demyelination: Case series and review of the literature. Pediatr Neurol 26: 18-25

McAlpine D (1931). Acute disseminated encephalomyelitis: its sequelay and its relationship to disseminated sclerosis. Lancet $846-852$ 
Menge T, Kieseier BC, Nessler S, Hemmer B, Hartung HP, Stüve O (2007). Acute disseminated encephalomyelitis: an acute hit against the brain. Curr. Opin. Neurol. 20 (3): 247-54.

Mikaeloff Y, Adamsbaum C, Husson B, Vallée L, Ponsot G, Confavreux C, Tardieu M, Suissa S; KIDMUS Study Group on Radiology (2004). MRI prognostic factors for relapse after acute CNS inflammatory demyelination in childhood. Brain 127(9): 1942-7

Mikaeloff Y, Caridade G, Rossier M, Suissa S, Tardieu M (2007). Parental smoking at home and the risk of childhood onset multiple sclerosis in children. Brain 130: 2589-95

Mikaeloff Y, Moreau T, Debouverie M, Pelletier J, Lebrun C, Gout O, Pedespan JM, Van Hulle C, Vermersch P, Ponsot G (2001) Interferon-beta treatment in patients with childhood-onset multiple sclerosis. J Pediatr 139: 443-6.

Mikaeloff Y, Caridade G, Tardieu M, Suissa S; KIDSEP study group of the French Neuropediatric Society (2008). Effectiveness of early beta interferon on the first attack after confirmed multiple sclerosis: A comparative cohort study. Eur J Paediatr Neurol 12: 205-9.

Mikaeloff Y, Caridade G, Assi S, Suissa S, Tardieu M (2006). Prognostic factors for early severity in a childhood multiple sclerosis cohort. Pediatrics 118: 1133-9.

Miller HG, Stanton JB, Gibbons JL (1956). Parainfectious encephalomyelitis and related syndromes. QJM 25: 427-505

Miller DH, Barkhof F, Frank JA, Parker GJ, Thompson AJ (2002). Measurement of atrophy in multiple sclerosis: pathological basis, methodological aspects and clinical relevance. Brain 125: 1676-1695

Morrow SA, Stoian CA, Dmitrovic J, Chan SC, Metz LM (2004). The bioavailability of IV methylprednisolone and oral prednisone in multiple sclerosis. Neurology 63: 107980.

Moscovich DG, Singh MB, Eva FJ, Puri BK (1995). Acute disseminated encephalomyelitis presenting as an acute psychotic state. J Nerv Ment Dis 183: 116-117

Morissey SP, Miller DH, Kendall BE, Kingsley DPE,Kelly MA, Francis DA, Macmanus DG, Mcdonald WI. The significance of brain magnetic resonance imaging abnormalities at presentation with clinically isolated syndromes suggestive of multiple sclerosis. Brain (1993) 116 (1): 135-146

Murray TJ (2005). Multiple Sclerosis: The History of a Disease, Demos Medical Publishing, ISBN 1-888799-80-3, New York

Murthy SN, Faden HS, Cohen ME, Bakshi R (2002). Acute disseminated Encephalomyelitis in children. Paediatrics 110: e21

Ness, J.M., Chabas, D., Sadovnick, A. Pohl D, Banwell B, Weinstock-Guttman B; International Pediatric MS Study Group (2007). Clinical features of children and adolescents with mulptiple sclerosis. Neurology 68: S37-45.

O'Riordan JI, Gallagher HL, Thompson AJ, Howard RS, Kingsley DP, Thompson EJ, McDonald WI, Miller DH (1996). Clinical, CSF, and MRI findings in Devic's neuromyelitis optica. J Neurol Neurosurg Psychiatry 60(4): 382-7.

Okuda DT, Mowry EM, Beheshtian A, Waubant E, Baranzini SE, Goodin DS, Hauser SL, Pelletier D (2009). Incidental MRI anomalies suggestive of multiple sclerosis: the radiologically isolated syndrome. Neurology 72(9): 800-805 
Pearce JM (2005). "Neuromyelitis optica" (abstract). Spinal Cord 43 (11): 631-634.

Pidcock FS, Krishnan C, Crawford TO, Salorio CF, Trovato M, Kerr DA (2007). Acute transverse myelitis in childhood: center-based analysis of 47 cases. Neurology 68: 1474-1480.

Pittock SJ, Lucchinetti CF (2006). Inflammatory transverse myelitis: evolving concepts. Curr Opin Neurol. 19: 362-368

Pittock SJ, Wingerchuk DM, Krecke K, Lennon VA, Lucchinetti CF, Weinshenker BG (2005). Brain abnormalities in patients with neuromyelitis optica (NMO). Neurology 2005;64: A39.

Pohl D, Rostasy K, Treiber-Held S Brockmann K, Gärtner J, Hanefeld F (2006). Pediatric multiple sclerosis: detection of clinically silent lesions by multimodal evoked potentials. J Pediatr 149: 125-127.

Poser S, Luer W, Bruhn H, Frahm J, Briick Y, Felgenhauer K (1992). Classification and Noninvasive diagnosis. Acta Neurologica Scand. 86: 579-585

Pradhan S, Gupta RK, Ghosh D (1997). Parainfectious myelitis: three distinct clinicoimagiological patterns with prognostic implications. Acta Neurol Scand 5: 241-7.

Pretorius ML, Loock DB, Ravenscroft A, Schoeman JF (1998). Demyelinating Disease of the Schilder Type in 3 young SA children: dramatic response to Steroids. J Child. Neurol 13: 197- 201

Pugliatti M, Riise T, Sotgiu MA, Satta WM, Sotgiu S, Pirastru MI, Rosati G (2006). Evidence of early childhood in the susceptibility period in multiple sclerosis: space-time cluster analysis in a Sardinian population. Am J Epidemiol 164. 326-33

Ramagopalan SV, Maugeri NJ, Handunnetthi L, Lincoln MR, Orton S, Dyment DA, DeLuca G, Herrera BM, Chao MJ, Sadovnick DA, Ebers GC, Knight JC (2009). Expression of the Multiple Sclerosis-Associated MHC Class II Allele HLA-DRB1*1501 Is Regulated by Vitamin D. PLoS Genet 5(2): e1000369

Renoux C, Vukusic S, Mikaeloff Y, Edan G, Clanet M, for the Adult Neurology Departments KIDMUS Study Group (2007). Natural History of Multiple Sclerosis with Childhood Onset. NEJM 356 (5): 2603-2613

Ruggieri M, Iannetti P, Polizzi A, Pavone L, Grimaldi LM (2004). Multiple sclerosis in children under 10 years of age. Neurol Sci 25 (4): S326-S335.

Sadovnick AD, Duquette, P, Herrera B, Yee IM, Ebers GC (2007). A timing-of-birth effect on multiple sclerosis clinical phenotype. Neurology 69. 60-2.

Saito H, Endo M, Takase S, Itahara K (1998). Acute disseminated encephalomyelitis after influenza vaccination. Arch Neurol 37: 564-6

Schwaz S, Mohar A, Knauth M (2001). Acute disseminated encephalomyelitis: a follow-up study of 40 patients. Neurology 56: 1383-1318

Sebire G, Hollenberg H, Meyer L, Huault G, Landrieu P, Tardieu M (1997). High dose methylprednisolone in severe acute transverse myelopathy. Arch Dis Child 76: $167-8$.

Shaw CM, Alvord EC (1987). Multiple sclerosis beginning in infancy. Journal of Child Neurology 2: 252-256

Sheldon JJ, Siddharthan R, Tobias J, Sherenata WA, Soila K, Viamonte M (1985). MR imaging of multiple sclerosis: Comparison with clinical and CT examinations in 74 patients. Am J Roentgenol 145 (5): 957-64. 
Simone IL, Carrara D, Tortorella C, Liguori M, Lepore V, Pellegrini F, Bellacosa A, Ceccarelli A, Pavone I, Livrea (2002). Course and prognosis in early-onset MS: comparison with adult-onset forms. Neurology 24; 59(12): 1922-8.

Sindern E, Haas J, Stark E, Wurster U (1992). Early onset MS under the age of 16: clinical and paraclinical features. Acta Neurol Scand 86: 280-4.

Singh S, Prabhakar S, Korah IP, Warade SS, Alexander M (2002). Acute disseminated encephalomyelitis and multiple sclerosis: Magnetic resonance imaging differentiation. Australas Radiol 44: 404-411

Smith AB (2009). Imaging of Demyelinating diseases, In: Radiological Pathology, $8^{\text {th }}$ edition, Craig DW, Chung EM, Galvin JR, Glassman LM, Lewis RB, Murphey MD, Smith AB (eds), pp1103-9, American Registry of Pathology,ISBN 1-933477-28-8, Washington DC

Stone MJ, Hawkins CP (2007). A medical overview of encephalitis. Neuropsychol Rehabil 17 (4-5): 429-49

Straub J, Chofflon M, Delavelle J (1997). Early high dose intravenous methylprednisolone in acute disseminated encephalomyelitis: A successful recovery. Neurology 49: 1145-7.

Straussberg R, Schonfeld T, Weitz R, Karmazyn B, Harel L (2001). Improvement of atypical acute disseminated encephalomyelitis with steroids and intravenous immunoglobulins. Pediatr. Neurol. 24 (2): 139-43

Stricker RB, Miller RG, Kiprov DD (1992). Role of plasmapharesis in acute disseminated (postinfectious) encephalomyelitis. J Clin Apheresis 7: 173-9.

Tenembaum S, Chitnis Tanuja MD, Ness Jayne, Hahn Jin S for the International Pediatric MS Study Group (2007). Acute Disseminated Encephalomyelitis. Neurology 68(16): s23-s26

Tenembaum S, Chamoles N, Fejerman N (2002). Acute disseminated encephalomyelitis: a long-term follow-up study of 84 pediatric patients. Neurology 59: 1224-1231.

Tenembaum SN, Segura MJ (2006). Interferon beta-1a treatment in childhood and juvenileonset multiple sclerosis. Neurology 67: 511-13

Tintore M, Rovira A, Arrambide G, Mitjana R, Río J, Auger C, Nos C, Edo MC, Castillo J, Horga A, Perez-Miralles F, Huerga E, Comabella M, Sastre-Garriga J, Montalban X (2010). Brainstem lesions in clinically isolated syndromes. Neurology 75 (21): 19331938

Tintoré M, Rovira A, Martínez MJ, Rio J, Díaz-Villoslada P, Brieva L, Borrás C, Grivé E, Capellades J, Montalban X (2000). Isolated demyelinating syndromes: comparison of different MR imaging criteria to predict conversion to clinically definite multiple sclerosis. AJNR Am J Neuroradiol 21: 702-706.

Transverse Myelitis Consortium Working Group (2002). Proposed diagnostic criteria and nosology of acute transverse myelitis. Neurology 59: 499-505

Tselis AC, Lisak RP (1998). Acute disseminated encephalomyelitis. In: Clinical neuroimmunology. Antel J, Birnbaum G, Hartung HP, eds. pp116-47, Blackwell Science,, Boston

Van der Knaap MS, van der Grond J, Luyten PR, den Hollander JA, Nauta JJP, Valk J (1992). $1 \mathrm{H}$ and $31 \mathrm{P}$ magnetic resonance spectroscopy of the brain in degenerative cerebral disorders. Ann Neurol 31: $202 \pm 211$ 
Wingerchuk DM, Lennon VA, Pittock SJ, Lucchinetti CF, Weinshenker BG (2006).Revised diagnostic criteria for neuromyelitis optica. Neurology 66 (10): 1485-1489.

Wingerchuk DM, Weinshenker BG (2005). Neuromyelitis Optica. Curr Treat Options Neurol 7(3): 173-82 


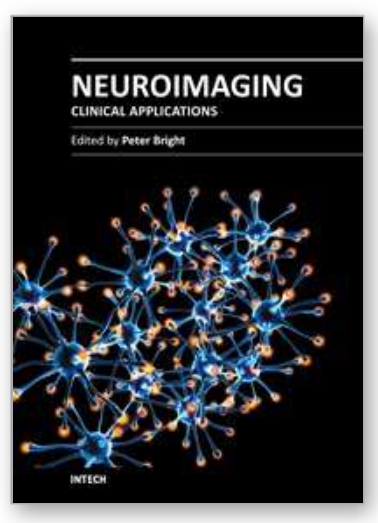

\author{
Neuroimaging - Clinical Applications \\ Edited by Prof. Peter Bright
}

ISBN 978-953-51-0200-7

Hard cover, 576 pages

Publisher InTech

Published online 09, March, 2012

Published in print edition March, 2012

Modern neuroimaging tools allow unprecedented opportunities for understanding brain neuroanatomy and function in health and disease. Each available technique carries with it a particular balance of strengths and limitations, such that converging evidence based on multiple methods provides the most powerful approach for advancing our knowledge in the fields of clinical and cognitive neuroscience. The scope of this book is not to provide a comprehensive overview of methods and their clinical applications but to provide a "snapshot" of current approaches using well established and newly emerging techniques.

\title{
How to reference
}

In order to correctly reference this scholarly work, feel free to copy and paste the following:

R. Govender, Jo M. Wilmshurst and Nicky Wieselthaler (2012). Acquired Demyelinating Disorders of the CNS in Children, Neuroimaging - Clinical Applications, Prof. Peter Bright (Ed.), ISBN: 978-953-51-0200-7, InTech, Available from: http://www.intechopen.com/books/neuroimaging-clinical-applications/acquired-demyelinatingdisorders-of-the-cns-in-children

\section{INTECH}

open science | open minds

\section{InTech Europe}

University Campus STeP Ri

Slavka Krautzeka 83/A

51000 Rijeka, Croatia

Phone: +385 (51) 770447

Fax: +385 (51) 686166

www.intechopen.com

\section{InTech China}

Unit 405, Office Block, Hotel Equatorial Shanghai

No.65, Yan An Road (West), Shanghai, 200040, China

中国上海市延安西路65号上海国际贵都大饭店办公楼 405 单元

Phone: +86-21-62489820

Fax: +86-21-62489821 
(C) 2012 The Author(s). Licensee IntechOpen. This is an open access article distributed under the terms of the Creative Commons Attribution 3.0 License, which permits unrestricted use, distribution, and reproduction in any medium, provided the original work is properly cited. 